\title{
Linking the Character of the Metal-Ligand Bond to the Ligand NMR Shielding in Transition-Metal Complexes: NMR Contributions from Spin-Orbit Coupling
}

Jan Novotný, ${ }^{\dagger \dagger}$ Jan Vícha, ${ }^{\# \odot ~ P a n k a j ~ L . ~ B o r a, ~}{ }^{\dagger, \S}$ Michal Repisky, ${ }^{\nabla}$ Michal Straka, ${ }^{\dagger, I[0}$

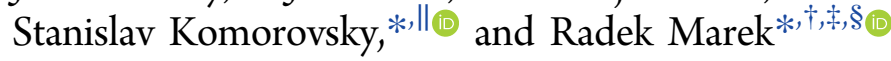

${ }^{\dagger}$ CEITEC - Central European Institute of Technology, Masaryk University, Kamenice 5/A4, CZ-62500 Brno, Czechia

${ }^{\ddagger}$ National Center for Biomolecular Research, Faculty of Science and ${ }^{\S}$ Department of Chemistry, Faculty of Science, Masaryk

University, Kamenice 5, CZ-62500 Brno, Czechia

${ }^{\#}$ Centre of Polymer Systems, University Institute, Tomas Bata University in Zlín, Třída T. Bati, 5678, CZ-76001 Zlín, Czechia

${ }^{\nabla}$ Center for Theoretical and Computational Chemistry, Department of Chemistry, UiT - The Arctic University of Norway, N-9037 Tromsø, Norway

II Institute of Organic Chemistry and Biochemistry of the ASCR, Flemingovo nám. 2, CZ-16610 Praha, Czechia

"Institute of Inorganic Chemistry, Slovak Academy of Science, Dúbravská cesta 9, SK-84536 Bratislava, Slovakia

Supporting Information

ABSTRACT: Relativistic effects significantly affect various spectroscopic properties of compounds containing heavy elements. Particularly in Nuclear Magnetic Resonance (NMR) spectroscopy, the heavy atoms strongly influence the NMR shielding constants of neighboring light atoms. In this account we analyze paramagnetic contributions to NMR shielding constants and their modulation by relativistic spin-orbit effects in a series of transition-metal complexes of $\mathrm{Pt}(\mathrm{II}), \mathrm{Au}(\mathrm{I}), \mathrm{Au}(\mathrm{III})$, and $\mathrm{Hg}$ (II). We show how the paramagnetic NMR shielding and spinorbit effects relate to the character of the metal-ligand $(\mathrm{M}-\mathrm{L})$ bond. A correlation between the (back)-donation character of the $\mathrm{M}-\mathrm{L}$ bond in $\mathrm{d}^{10} \mathrm{Au}(\mathrm{I})$ complexes and the propagation of the spin-orbit (SO) effects from $\mathrm{M}$ to $\mathrm{L}$ through the $\mathrm{M}-\mathrm{L}$ bond influencing the ligand NMR shielding via the Fermi-contact mechanism is found and rationalized by

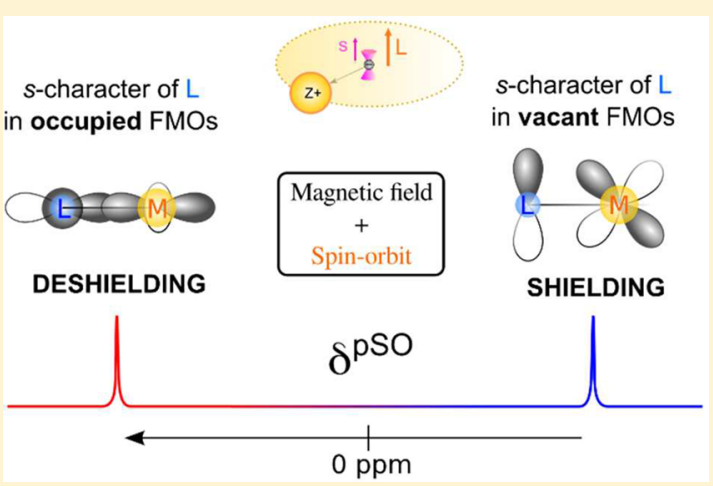
using third-order perturbation theory. The SO effects on the ligand NMR shielding are demonstrated to be driven by both the electronic structure of $\mathrm{M}$ and the nature of the trans ligand, sharing the $\sigma$-bonding metal orbital with the NMR spectator atom L. The deshielding paramagnetic contribution is linked to the $\sigma$-type $\mathrm{M}-\mathrm{L}$ bonding orbitals, which are notably affected by the trans ligand. The SO deshielding role of $\sigma$-type orbitals is enhanced in $\mathrm{d}^{10} \mathrm{Hg}$ (II) complexes with the $\mathrm{Hg} 6 p$ atomic orbital involved in the $\mathrm{M}-\mathrm{L}$ bonding. In contrast, in $\mathrm{d}^{8} \mathrm{Pt}$ (II) complexes, occupied $\pi$-type orbitals play a dominant role in the SO-altered magnetic couplings due to the accessibility of vacant antibonding $\sigma$-type MOs in formally open $5 \mathrm{~d}$-shell $\left(\mathrm{d}^{8}\right)$. This results in a significant SO shielding at the light atom. The energy- and composition-modulation of $\sigma$-vs $\pi$-type orbitals by spin-orbit coupling is rationalized and supported by visualizing the SO-induced changes in the electron density around the metal and light atoms (spin-orbit electron deformation density, SO-EDD).

\section{INTRODUCTION}

Nuclear Magnetic Resonance (NMR) spectroscopy is an indispensable structural tool in the modern analytical arsenal of chemists and structural biologists. This spectroscopic method matured at the end of the 20th century by an expansion of multidimensional chemical-shift correlation techniques $^{1}$ and a sophisticated mapping of nuclear-spin relaxation processes. $^{2,3}$ Despite very early discoveries of immense importance of nuclear magnetic shielding as a probe to internal structure of matter, its link to the chemical bond concepts is not always well established and understood. This applies particularly to the molecules of open-shell nature or systems containing heavy element(s).

The NMR shielding constant $(\sigma)$ for any atom can be formally split into the diamagnetic $\left(\sigma^{\mathrm{d}}\right)$ and paramagnetic $\left(\sigma^{\mathrm{p}}\right)$ contributions. This partitioning is not unique but provides an intuitive picture of the shielding mechanism. The diamagnetic contribution reflects the total ground-state electron density around the NMR spectator atom and is relatively invariant to the change in its chemical environment. In contrast, the

Received: May 2, 2017

Published: July 6, 2017 
paramagnetic contribution originates in couplings between the occupied and vacant frontier molecular orbitals (MOs) in the presence of magnetic field and provides important chemical information about the molecular electronic structure and bonding. ${ }^{4,5}$ In the following, we focus on the NMR shielding constants of light ligand atoms (L) in compounds containing heavy atoms (HA) where relativistic effects, which originate at the $\mathrm{HA}$ and propagate to the neighboring $\mathrm{L}$, play a significant role. $^{6-11}$ The relativistic contribution to the NMR shielding constant of $\mathrm{L}$ is typically heavily modulated by the spin-orbit (SO) coupling term $\left(\sigma^{\mathrm{SO}}\right):^{12-15}$

$$
\sigma=\sigma^{\mathrm{d}}+\sigma^{\mathrm{p}}+\sigma^{\mathrm{SO}}
$$

The $\sigma^{\text {SO }}$ can be obtained as a perturbation to nonrelativistic or scalar-relativistic one-component (1c) calculations. ${ }^{16-18}$ Traditionally, these 1c approaches are used in chemistry to establish a link between the electronic molecular structure and the shielding mechanism for individual atoms. In calculations of NMR shielding constant using variational treatment of relativistic effects, such as two-component (2c) SO-ZORA or four-component (4c) DKS approaches used in this work, the $\sigma$ is naturally relativistic. The spin-orbit contribution to $\sigma\left(\sigma^{\mathrm{SO}}\right)$ is then obtained as a difference between the relativistic $2 \mathrm{c}\left(\sigma_{2 \mathrm{c}}\right)$ or $4 \mathrm{c}\left(\sigma_{4 \mathrm{c}}\right)$ and $1 \mathrm{c}\left(\sigma_{1 \mathrm{c}}\right)$ values:

$$
\sigma^{\mathrm{SO}} \equiv \sigma_{2 \mathrm{c} / 4 \mathrm{c}}-\sigma_{1 \mathrm{c}}
$$

As mentioned above, the diamagnetic contribution typically does not vary significantly in a series of similar compounds, and, therefore, the paramagnetic part governs the overall trends in SO NMR shielding constants. In analogy to eq 2 , we define $\sigma^{\mathrm{pSO}}$ as

$$
\sigma^{\mathrm{pSO}} \equiv \sigma_{2 \mathrm{c} / 4 \mathrm{c}}^{\mathrm{p}}-\sigma_{1 \mathrm{c}}^{\mathrm{p}}
$$

The SO effects on the NMR chemical shifts have been recognized and related to the mechanism of the indirect nuclear spin-spin coupling as early as in the late 1970s. ${ }^{19-21}$ During the recent three decades, several factors have been described to influence the SO effects of Heavy Atom on the Light Atom (HALA): ${ }^{6} s$-character of the light atom in the HA-LA bond, ${ }^{11}$ energy gap between involved occupied and vacant molecular orbitals, ${ }^{22,23}$ orbital character of the heavy atom in the HA-LA bond, ${ }^{7}$ formal oxidation state of the heavy atom, ${ }^{24}$ and covalence/ionicity of the HA-LA bond. ${ }^{8,25,26}$ All these factors are related to the character of the HA-LA bond.

In the field of transition-metal (M) complexes, the spinorbit contribution to the NMR shielding constant of the ligand spectator atom $\mathrm{L}, \sigma^{\mathrm{SO}}(\mathrm{L})$, has recently been shown to correlate quantitatively with the $5 d$ and $6 p$ character of $\mathrm{M}$ in the metalligand $(\mathrm{M}-\mathrm{L})$ bond $^{7}$ and with the covalence of the $\mathrm{M}-\mathrm{L}$ bond. ${ }^{8}$ In addition, the substituent $\mathrm{X}$ in the trans position to $\mathrm{L}$ effectively alters both the character of the $\mathrm{M}-\mathrm{L}$ bond and $\sigma^{\mathrm{SO}}(\mathrm{L})^{7,8,27,28}$ via the well-known structural trans effect. ${ }^{29,30}$ This effect originates in the fact that the two trans-arranged ligands share a single metal atomic orbital ( $\mathrm{AO}$ ) in their bonding. As a result, the polarization of metal-centered $\mathrm{AO}$ by one of the substituents induces a significant repolarization of the same orbital on the side of the second substituent. Both substituents thus mutually influence their bonding character with the metal center - increasing polarity of one bond (smaller metal AO character in the bond) results in a more covalent bonding in the trans position.
In this contribution, we provide a chemical link between the structurally altered paramagnetic contributions to the light atom NMR shielding constants and the energy characteristics of $\mathrm{M}-\mathrm{L}$ bonding in a series of transition-metal complexes of $\mathrm{Pt}(\mathrm{II}), \mathrm{Au}(\mathrm{I}), \mathrm{Au}(\mathrm{III})$, and $\mathrm{Hg}(\mathrm{II})$, Figure 1. Both the

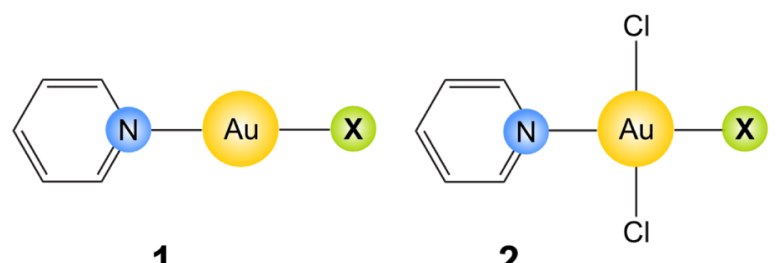

1

2
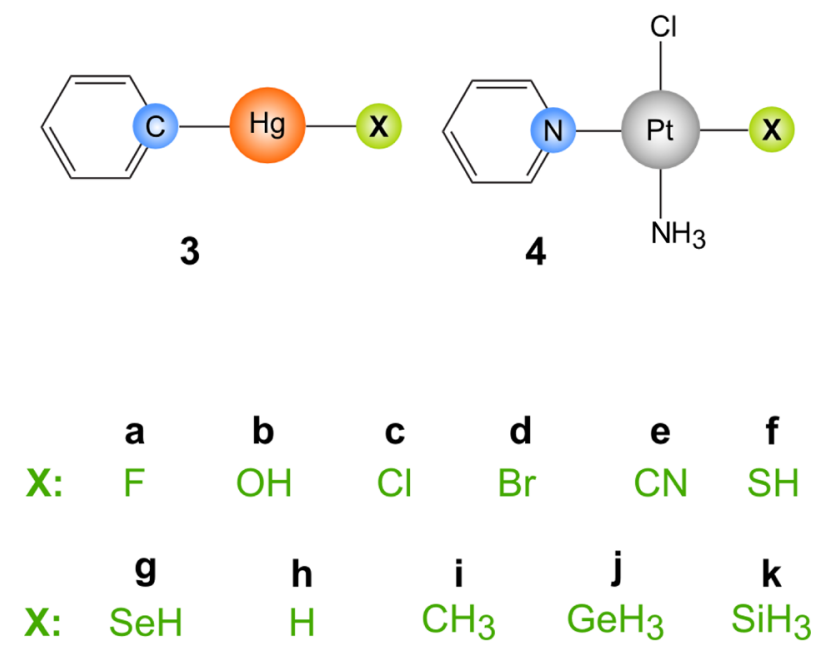

Figure 1. Structures of studied complexes $1 \mathrm{a}-\mathbf{4 k}$. The trans substituent $\mathrm{X}$ is highlighted in green, and the NMR spectator ligand atoms $\mathrm{L}$ are highlighted in blue.

relativistic spin-orbit effects on $\sigma^{\mathrm{p}}$ and character of the $\mathrm{M}-\mathrm{L}$ bonding are shown to be altered effectively by the structural trans effect (donation/back-donation efficiency). The character of $\mathrm{M}-\mathrm{L}$ bonding is described by canonical molecular orbitals (MOs) and the energy decomposition analysis combined with natural orbitals for chemical valence (EDA-NOCV). We introduce a novel schematic representation of the SO HALA NMR (de)shielding mechanism based on the third-order perturbation theory. It represents an additional tool for chemists to relate the nature of chemical bonding with the ligand NMR shielding constant. The central question of this work is how do the changes in $\sigma$ - and $\pi$-contributions to the $\mathrm{M}-\mathrm{L}$ bond affect SO contributions to the NMR shielding constant of the spectator atom L. The sign and magnitude of structural effects on $\sigma^{\mathrm{P}}(\mathrm{L})$ and $\sigma^{\mathrm{SO}}(\mathrm{L})$ tensors are rationalized.

\section{THEORETICAL BACKGROUND}

In the following text, the symbol $\sigma$ refers to the NMR shielding constant but denotes also the symmetry of the $\mathrm{M}-\mathrm{L}$ bonding MOs. The symbol for NMR shielding constant typically contains a superscript representing contribution term (e.g., $\sigma^{\mathrm{pSO}}$ ) whereas the symbol for MO symmetry is specified by the bond involved (e.g., $\sigma_{\mathrm{M}-\mathrm{L}}$ ).

In the absence of SO coupling (nonrelativistic theory), paramagnetic contribution to the NMR shielding constant of a ligand atom $\mathrm{L}\left(\sigma^{\mathrm{p}}(\mathrm{L})\right)$ is theoretically formulated by the Ramsey-type coupling formula (neglecting contribution from kernels, see the Supporting Information $)^{4}$ 


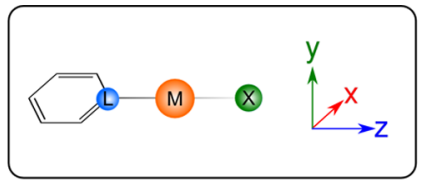

\section{PARAMAGNETIC (local) \\ a) $\mathrm{MO} \longrightarrow \mathrm{MO}^{*}$}

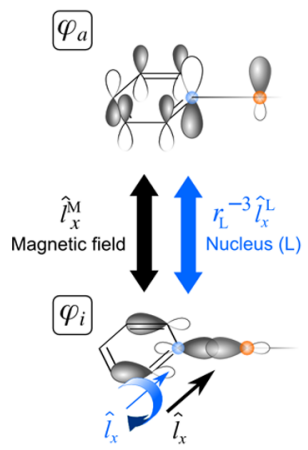

$\left\langle\varphi_{a}\left|r_{\mathrm{L}}^{-3} \hat{l}_{x}^{\mathrm{L}}\right| \varphi_{i}\right\rangle$

$\left\langle\varphi_{a}\left|\hat{l}_{x}^{\mathrm{M}}\right| \varphi_{i}\right\rangle$ b) $\mathrm{MO} \longrightarrow \mathrm{MO} \longrightarrow \mathrm{MO}^{*}$

$(\mathrm{SO} / \mathrm{FC} \triangle)$

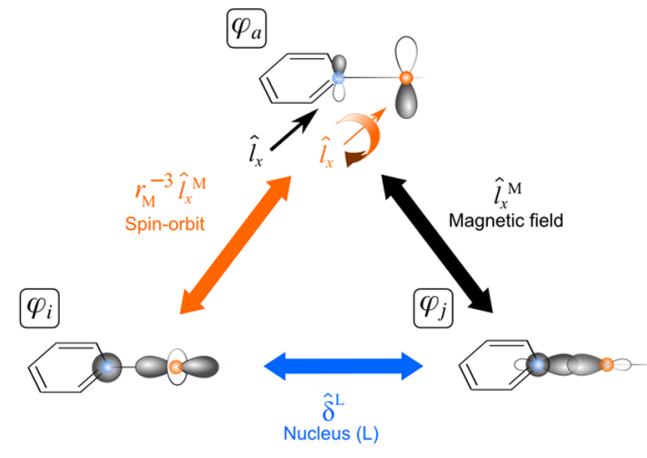

$\left\langle\varphi_{a}\left|r_{\mathrm{M}}^{-3} \hat{l}_{x}^{\mathrm{M}}\right| \varphi_{i}\right\rangle$

$\left\langle\varphi_{i}\left|\hat{\delta}^{L}\right| \varphi_{j}\right\rangle$

$\left\langle\varphi_{j}\left|\hat{l}_{x}^{\mathrm{M}}\right| \varphi_{a}\right\rangle$
SPIN-ORBIT

(nonlocal)

c) $\mathrm{MO} \hookrightarrow \mathrm{MO}^{*} \rightarrow \mathrm{MO}^{*}$

$\left(\mathrm{SO} / \mathrm{FC}^{\nabla}\right)$

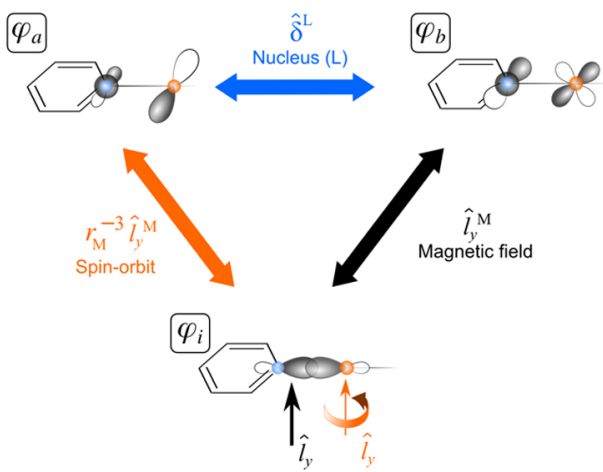

$\left\langle\varphi_{i}\left|r_{\mathrm{M}}^{-3} \hat{l}_{y}^{\mathrm{M}}\right| \varphi_{a}\right\rangle$

$\left\langle\varphi_{a}\left|\hat{\delta}^{L}\right| \varphi_{b}\right\rangle$

$\left\langle\varphi_{b}\left|\hat{l}_{y}^{\mathrm{M}}\right| \varphi_{i}\right\rangle$

Figure 2. A schematic graphical representation of a) the local nature of Ramsey-type paramagnetic coupling, $\sigma^{\mathrm{p}}(\mathrm{L})$. As an example, the paramagnetic coupling arising from the L-centered NMR active $\mathrm{MO}_{\sigma_{\mathrm{L}-\mathrm{M}}} \leftrightarrow \mathrm{MO}_{\pi_{\mathrm{L}-\mathrm{M}}}^{*}\left(\varphi_{i} \leftrightarrow \varphi_{a}\right.$ in eq 2) transition is shown. A nonlocal character of the SO contribution to $\sigma(\mathrm{L}), \sigma^{\mathrm{SO}}(\mathrm{L})$, which originates at the metal atom $\mathrm{M}$ and propagates to the light ligand atom $\mathrm{L}$ via $\left.\mathbf{b}\right)$ the $\mathrm{SO} / \mathrm{FC}^{\Delta}$ mechanism involving two occupied MOs: $\varphi_{i} \leftrightarrow \varphi_{j} \leftrightarrow \varphi_{a}$ (see eq 6) or c) the SO/FC ${ }^{\nabla}$ mechanism involving two vacant MOs: $\varphi_{i} \leftrightarrow \varphi_{a} \leftrightarrow \varphi_{b}$ (see eq 7). The interaction of an external magnetic field with the electron orbital motion, given by an angular-momentum operator $\hat{l}$, is color-coded in black. The ground-state perturbation caused by the nuclear magnetic moment of the spectator atom L via paramagnetic spin-orbit (PSO in a) and Fermicontact ( FC in $\mathbf{b}$ and $\mathbf{c}$ ) interaction is coded in blue, and the $\mathrm{SO}$ coupling originating from the metal center $\mathrm{M}$ is coded in orange.

$$
\boldsymbol{\sigma}^{\mathrm{P}}(\mathrm{L}) \approx \frac{1}{c^{2}} \sum_{i=1}^{\mathrm{occ}} \sum_{a=1}^{\mathrm{vac}} \frac{\left\langle\varphi_{i}\left|\hat{\boldsymbol{l}}^{\mathrm{M}}\right| \varphi_{a}\right\rangle\left\langle\varphi_{a}\left|r_{\mathrm{L}}^{-3} \hat{\boldsymbol{l}}^{\mathrm{L}}\right| \varphi_{i}\right\rangle}{\varepsilon_{i}-\varepsilon_{a}}
$$

Here $\varphi_{i}\left(\varphi_{a}\right)$ denotes the occupied (vacant) molecular orbital, $\varepsilon_{i}\left(\varepsilon_{a}\right)$ stands for occupied (vacant) one-electron energy, and $r_{\mathrm{L}}$ is the position vector relative to the coordinates of the ligand spectator atom L. The Ramsey formula describes magnetic coupling between individual occupied-vacant MO-pairs through the angular momentum operator, $\hat{l}^{\mathrm{M}}$, and the paramagnetic nuclear-spin-electron-orbit (PSO) operator $\left(r_{\mathrm{L}}^{-3} \hat{l}^{\mathrm{L}}\right)$. Since PSO is of highly local nature (electron orbital motion coupled with nuclear magnetic moment of the spectator atom L) the trenddetermining contributions to $\sigma^{\mathrm{p}}(\mathrm{L})$ arise from the magnetically coupled $\mathrm{MO} \leftrightarrow \mathrm{MO}^{*}$ pairs that have both: a significant admixture of AOs centered on $\mathrm{L}$ and a small energy gap $\varepsilon_{i}-$ $\varepsilon_{a}$. In compounds $\mathbf{1 - 4}$, the paramagnetic shielding constant of the aromatic nitrogen/carbon is dominated by the Ramsey-type couplings between the occupied $\sigma_{\mathrm{M}-\mathrm{L}}\left(2 p_{z}\right.$ character of L) or $\sigma_{\mathrm{L}-\mathrm{C}}\left(2 p_{x}\right.$ character of $\left.\mathrm{L}\right)$ and vacant $\pi^{*}$-type $\left(2 p_{y}\right.$ character of L) MOs, ${ }^{31-35}$ Figure $2 \mathrm{a}$.

Note that both operators in eq 4 are referenced relative to a different coordinate center (so-called gauge origin), which is either the ligand atom $\mathrm{L}$ or the metal center $\mathrm{M}$, as indicated by the superscript. Although the exact physical theory allows an arbitrary change of the gauge origin in the angular momentum operator responsible for the interaction with external magnetic field (e.g., $\hat{l}^{\mathrm{M}} \rightarrow \hat{l}^{\mathrm{L}}$ ), this requires an infinite number of vacant orbitals available. In practice, however, simple and generalizing chemical concepts are useful only when a reasonably small number of the orbital excitations play a role and determine overall NMR trends. Note that the gauge origin variation will not significantly alter results of the Ramsey-type coupling for systems containing only light atoms (pyridine or benzene in compounds 1-4). Therefore, for the sake of simplicity the gauge origin is usually placed on the spectator atom L. In contrast, for systems containing a heavy atom $\mathrm{M}$, the gauge origin must be placed on $M$, otherwise the basis-set requirements and number of significant orbital excitations will increase enormously, ${ }^{36}$ prohibiting to establish a simple chemical link between NMR shielding and MO bonding theory.

In the relativistic picture, the spin-orbit (SO) coupling contribution to the paramagnetic NMR shielding of light atoms originates in our systems from the metal center $M$. The metal $p$ - and $d$-type AOs, which contribute to the NMR-active MOs, are split by the $\mathrm{SO}$ coupling, and this effect can be thought of as being propagated from the central atom $M$ to the ligand atom $L$ via the $\mathrm{M}-\mathrm{L}$ bond. There are two mechanisms involved Fermi-Contact (FC) and Spin-Dipolar (SD), eq 5. ${ }^{10,17}$

$$
\boldsymbol{\sigma}^{\mathrm{pSO}}(\mathrm{L})=\boldsymbol{\sigma}^{\mathrm{SO} / \mathrm{FC}}(\mathrm{L})+\boldsymbol{\sigma}^{\mathrm{SO} / \mathrm{SD}}(\mathrm{L})
$$

Note that both $\mathrm{SO} / \mathrm{FC}$ and $\mathrm{SO} / \mathrm{SD}$ terms are represented by highly local operators related to the spectator atom L. The SO/ FC term arises from the contact interaction between the nuclear and electron spins, and therefore $s$ orbitals of the spectator atom L play a significant role in this mechanism 
because only those orbitals have nonvanishing density at light atoms nuclei. In contrast, the $\mathrm{SO} / \mathrm{SD}$ term arises from the interaction between the nuclear and electron spin dipoles and has its origin in anisotropy of the electron spin density. For compounds investigated in this work, the SO/SD contribution to $\sigma^{\mathrm{SO}}(\mathrm{L})$ comes from the $2 p$ orbitals of the spectator atom $\left({ }^{13} \mathrm{C}\right.$ or $\left.{ }^{15} \mathrm{~N}\right)$. It is important to emphasize that the isotropic part of $\sigma^{\mathrm{pSO}}(\mathrm{L})$ is typically dominated by the SO/FC mechanism (see Table S1), ${ }^{10,17,37}$ which could be formulated in the third-order perturbation theory (PT3) formalism as (for full expressions, see the Supporting Information)

$$
\begin{aligned}
\boldsymbol{\sigma}^{\mathrm{SO} / \mathrm{FC}^{\Delta}}(\mathrm{L}) \approx & -\frac{1}{c^{4}} \sum_{i=1}^{\mathrm{occ}} \sum_{j=1}^{\text {occ }} \sum_{a=1}^{\mathrm{vac}} \frac{\left\langle\varphi_{a}\left|r_{\mathrm{M}}^{-3} \mathbf{1}^{\mathrm{M}}\right| \varphi_{i}\right\rangle\left\langle\varphi_{i}\left|\delta^{\mathrm{L}}\right| \varphi_{j}\right\rangle\left\langle\varphi_{j}\left|\hat{\mathbf{l}}^{\mathrm{M}}\right| \varphi_{a}\right\rangle}{\left(\varepsilon_{i}-\varepsilon_{a}\right)\left(\varepsilon_{j}-\varepsilon_{a}\right)} \\
& + \text { permutations } \\
\boldsymbol{\sigma}^{\mathrm{SO} / \mathrm{FC}^{\nabla}}(\mathrm{L}) \approx & +\frac{1}{c^{4}} \sum_{i=1}^{\mathrm{occ}} \sum_{a=1}^{\mathrm{vac}} \sum_{b=1}^{\mathrm{vac}} \frac{\left\langle\varphi_{i}\left|r_{\mathrm{M}}^{-3} \hat{\mathbf{l}}^{\mathrm{M}}\right| \varphi_{a}\right\rangle\left\langle\varphi_{a}\left|\delta^{\mathrm{L}}\right| \varphi_{b}\right\rangle\left\langle\varphi_{b}\left|\hat{\mathbf{I}}^{\mathrm{M}}\right| \varphi_{i}\right\rangle}{\left(\varepsilon_{i}-\varepsilon_{a}\right)\left(\varepsilon_{i}-\varepsilon_{b}\right)}
\end{aligned}
$$

As compared to the classical nonrelativistic Ramsey-type theory (eq 4), the perturbative expressions for $\mathrm{SO} / \mathrm{FC}^{\Delta}$ and $\mathrm{SO} / \mathrm{FC}^{\nabla}$ require a mutual interplay among three perturbative operators and involve additional occupied $\left(\varphi_{j}\right)$ and vacant $\left(\varphi_{b}\right)$ MOs. Because all the expressions make use of identical sets of nonrelativistic or scalar-relativistic MOs, one can establish an intuitive link between the PT3 theory and the classical Ramsey's theory. A schematic graphical representation of the relations is given for a specific $\mathrm{M}-\mathrm{L}$ arrangement in Figure 2 .

The three perturbations involved in eqs 6 and 7 are the SO coupling, Fermi-contact, and angular-momentum operators. The role of the SO coupling term, which has in analogy to PSO a rather local character, is to provide a coupling between two metal-based $p$ - or $d$-type orbitals. Note that this operator is color-coded in orange to highlight its origin to the atom $\mathrm{M}$ $\left(r_{\mathrm{M}}^{-3} \hat{l}^{\mathrm{M}}\right)$. The role of the Fermi-contact interaction term, highlighted in blue and represented by $\delta^{\mathrm{L}}$ function, is associated with the electronic structure around the spectator atom L. In contrast to the PSO term, FC represents a direct interaction of the electron spin density with the spectator nucleus. The remaining $\mathrm{MO}$ coupling term is linked to an applied external magnetic field by means of the angular-momentum operator $\hat{l}$. A mutual interplay among all three perturbations is shown schematically by a MO triangular diagram in Figure 2. As an example, we consider for a specific combination of the perturbations in Figures $2 \mathrm{~b}$ and $2 \mathrm{c}$ two distinct $\mathrm{SO} / \mathrm{FC}^{\Delta}$ (eq 6) and $\mathrm{SO} / \mathrm{FC}^{\nabla}$ (eq 7) schemes that contribute to $\sigma^{\mathrm{SO} / \mathrm{FC}}(\mathrm{L}$ ) for systems investigated here. Note that two occupied MOs involved in $\mathrm{SO} / \mathrm{FC}^{\Delta}$ or two vacant $\mathrm{MOs}$ involved in $\mathrm{SO} / \mathrm{FC}^{\nabla}$ can be identical (see Section 4.3 and the Supporting Information for more details).

In contrast to classical Ramsey-type coupling (Figure 2a), the $\mathrm{SO} / \mathrm{FC}$ contribution is governed by electronic structure around both the metal atom $\mathrm{M}$ (SO coupling term in orange) and the ligand atom L (FC interaction term in blue). Therefore, SOactive MOs must be of a reasonable energy gap (see eqs 6 and 7) and of a particular symmetry and character of L and M. ${ }^{7,11}$ This implies the central role of the $\mathrm{M}-\mathrm{L}$ bond in propagating the SO effects. ${ }^{8,25,27}$

\section{METHODS}

3.1. Molecular Structures. The structures of $\mathrm{Au}(\mathrm{I})$, $\mathrm{Au}(\mathrm{III}), \mathrm{Hg}(\mathrm{II})$, and $\mathrm{Pt}$ (II) complexes 1-4 were minimized in vacuo using the $\mathrm{PBE0}^{38}$ functional and the def2-TZVPP basis sets for light atoms ${ }^{39}$ as implemented in Turbomole 6.3.1 code. $^{40}$ The relativistic effective-core potentials (ECPs) ${ }^{41}$ substituting 60 core electrons (MDF-60) were used for the heavy $\mathrm{Pt}, \mathrm{Au}$, and $\mathrm{Hg}$ atoms together with corresponding basis sets of def2-TZVPP quality. ${ }^{39,41}$ This computational level is referred to as PBE0/def2-TZVPP in this work and has been justified as the preferred choice in previous methodological studies of various transition-metal complexes. ${ }^{9,27,42-45}$

3.2. Electronic Structure Calculations. The Molecular Orbital (MO) Analysis was performed using the ADF software package. ${ }^{46,47}$ The PBE0 functional with the QZ4P basis set for the metal atom and TZ2P basis sets for light atoms ${ }^{48,49}$ was used. Scalar-relativistic effects were treated using zeroth-order regular approximation (ZORA) and spin-orbit effects using spin-orbit ZORA (SO-ZORA) as implemented in the ADF program. $^{50-52}$

EDA-NOCV Analysis ${ }^{53}$ was performed at the ZORA level (see previous paragraph) involving the Energy Decomposition Analysis (EDA) ${ }^{54,55}$ of Ziegler and Rauk, ${ }^{56-58}$ as implemented by Bickelhaupt and Baerends in ADF. ${ }^{55}$ According to EDA, the interaction energy $E_{\text {Int }}$ can be described as

$$
E_{\text {Int }}=E_{\text {Els }}+E_{\text {Pauli }}+E_{\text {Orb }}
$$

where $E_{\mathrm{Els}}$ is quasi-classical electrostatic component, $E_{\text {Pauli }}$ is Pauli repulsion term, and $E_{\mathrm{Orb}}$ is orbital component representing charge-transfer between interacting fragments as well as polarization of individual fragments. The contribution from the orbital term obtained by standard EDA decomposition was linked to Natural Orbitals for Chemical Valence (NOCV) analysis ${ }^{53,59}$ to decompose the electron deformation density (EDD) $)^{60,61}$ associated with bond formation into the individual components of the bond. We used this approach to quantify the energy stabilization $\left(E_{\mathrm{NOCV}}\right)$ brought about by individual pairings of occupied and vacant orbitals (NOCV channels).

QTAIM Analysis (Quantum Theory of Atoms in Molecules) was performed using the PBE functional, the def2-SVP basis set for light atoms, ${ }^{39}$ and MWB-60 ECP with def2-TZVPP for gold and mercury. ${ }^{41}$ Auxiliary s-type core electron functions were added manually to the molecular wave functions to model the ECP core electrons of $\mathrm{Au}$ and $\mathrm{Hg}$ atoms. ${ }^{8,62}$ The wave function was analyzed, and the delocalization index between all pairs of atoms was computed by the AIMAll suite of programs. ${ }^{63}$ The delocalization index, $\mathrm{DI}(\mathrm{M} \leftrightarrow \mathrm{L})$, quantifies the magnitude of electron sharing between two atomic basins and is a direct measure of covalence. ${ }^{64}$

3.3. NMR Shielding Constants. Two-Component Nuclear Magnetic Shielding was calculated by using the ADF2014 and ADF2016 codes at the scalar-relativistic ZORA and twocomponent SO-ZORA levels ${ }^{65,66}$ including GIAO (gauge including atomic orbitals). ${ }^{67}$ The comparison between direct $\sigma^{\mathrm{SO}} \mathrm{ADF}$ output and $\sigma_{2 \mathrm{c}}-\sigma_{1 \mathrm{c}}$ values is given in Table S2. The hybrid functional PBE0 (for comparison of PBE and PBE0 data, see Figure S1) with the QZ4P basis set for metal atoms and the TZ2P basis set for light atoms was used in these calculations (referred to as 2c). ${ }^{8,27,45,68}$ The spin-orbit contribution to the paramagnetic NMR shielding, $\sigma^{\mathrm{pSO}}$, was calculated as the difference between $2 c$ and $1 c$ paramagnetic 
Table 1. Correlation among Calculated Au-N Bond Lengths $\left(r_{\mathrm{Au}-\mathrm{N}}\right), \sigma^{\mathrm{SO}}\left({ }^{15} \mathrm{~N}\right)$-Tensors, ${ }^{a}$ Interaction Energies $\left(E_{\mathrm{Int}}^{\mathrm{Au}-\mathrm{N}}\right)$, Orbital Contributions to the Interaction Energies $\left(E_{\mathrm{Orb}}^{\mathrm{Au}-\mathrm{N}}\right){ }^{b}$ the Four Most Important EDA-NOCV Channels for Au-N Bonds, and the QTAIM Delocalization Indices $\mathrm{DI}(\mathrm{Au} \leftrightarrow \mathrm{N})$ for $\mathrm{PyAu} \mathrm{u}^{\mathrm{I}}$ Complexes $1 \mathrm{a}-\mathbf{1 k}^{c}$

\begin{tabular}{|c|c|c|c|c|c|c|c|c|c|c|c|c|}
\hline \multirow[b]{2}{*}{ compd - trans X } & \multirow[b]{2}{*}{$r_{\mathrm{Au}-\mathrm{N}}$} & \multicolumn{4}{|c|}{$\sigma^{\mathrm{SO}}\left({ }^{15} \mathrm{~N}\right)^{a}$} & \multirow[b]{2}{*}{$E_{\text {Int }}^{\mathrm{Au}-\mathrm{N}}$} & \multirow[b]{2}{*}{$E_{\mathrm{Orb}}^{\mathrm{Au}-\mathrm{N}}$} & \multicolumn{4}{|c|}{ EDA-NOCV channels } & \multirow[b]{2}{*}{$\mathrm{DI}(\mathrm{Au} \leftrightarrow \mathrm{N})$} \\
\hline & & $\sigma_{\text {iso }}^{\text {SO }}$ & $\sigma_{\mathrm{t}}^{\mathrm{SO}}$ & $\sigma_{\perp}^{\mathrm{SO}}$ & $\sigma_{\|}^{S O}$ & & & $\Delta E_{1}$ & $\Delta E_{2}$ & $\Delta E_{3}$ & $\Delta E_{4}$ & \\
\hline $1 a-F$ & 2.002 & +13.3 & 19.0 & 24.9 & -4.0 & -55.0 & -50.8 & -30.8 & -8.3 & -5.0 & -3.4 & 0.90 \\
\hline $\mathbf{l b}-\mathrm{OH}$ & 2.024 & +5.1 & 8.6 & 10.1 & -3.5 & -48.0 & -46.6 & -28.4 & -7.7 & -4.1 & -3.0 & 0.86 \\
\hline 1c $-\mathrm{Cl}$ & 2.045 & -4.5 & -7.0 & -2.6 & -4.0 & -47.1 & -45.4 & -28.2 & -6.8 & -4.5 & -2.8 & 0.82 \\
\hline $1 d-B r$ & 2.059 & -9.4 & -14.2 & -9.7 & -4.3 & -44.2 & -44.2 & -27.8 & -6.3 & -4.5 & -2.6 & 0.80 \\
\hline 1e $-\mathrm{CN}$ & 2.075 & -8.9 & -14.1 & -9.1 & -3.6 & -47.7 & -41.2 & -25.9 & -6.0 & -3.4 & -2.5 & 0.75 \\
\hline 1f - $\mathrm{SH}$ & 2.084 & -15.4 & -22.1 & -18.9 & -5.1 & -38.7 & -40.3 & -25.5 & -5.7 & -3.8 & -2.3 & 0.76 \\
\hline $1 \mathrm{~g}-\mathrm{SeH}$ & 2.092 & -18.1 & -26.9 & -22.0 & -5.3 & -36.3 & -39.9 & -25.6 & -5.5 & -3.9 & -2.2 & 0.75 \\
\hline $\mathbf{1 h}-\mathrm{H}$ & 2.141 & -19.2 & -29.1 & -24.1 & -4.5 & -31.5 & -30.9 & -20.3 & -4.1 & -2.5 & -1.8 & 0.67 \\
\hline $\mathbf{1 i}-\mathrm{CH}_{3}$ & 2.128 & -19.6 & -29.5 & -24.5 & -4.8 & -30.4 & -33.0 & -21.4 & -4.4 & -2.8 & -1.9 & 0.69 \\
\hline $\mathbf{1 j}-\mathrm{GeH}_{3}$ & 2.179 & -28.0 & -42.1 & -36.8 & -5.3 & -25.6 & -30.7 & -20.9 & -3.4 & -3.0 & -1.5 & 0.64 \\
\hline $\mathbf{1 k}-\mathrm{SiH}_{3}$ & 2.201 & -30.0 & -45.0 & -39.7 & -5.3 & -24.4 & -28.4 & -19.4 & -3.1 & -2.7 & -1.4 & 0.62 \\
\hline
\end{tabular}

${ }^{a}$ For the orientation of principal components of the ${ }^{15} \mathrm{~N}$ NMR shielding tensor wrt the coordination system, see Figure 3. Note that the differences in $\sigma^{\mathrm{SO}}$ originate mainly from the tangential $\left(\sigma_{\mathrm{t}}^{\mathrm{SO}}\right)$ and perpendicular $\left(\sigma_{\perp}^{\mathrm{SO}}\right)$ components of the ${ }^{15} \mathrm{~N}$ NMR shielding tensor. ${ }^{b}$ For the definition of $E_{\text {Int }}$ $E_{\text {Orb }}$, and EDA-NOCV channels, see Methods: Section 3.2. ${ }^{c}$ Bond lengths are given in $\AA, \sigma^{\text {SO }}\left({ }^{15} \mathrm{~N}\right)$ are given in ppm, DI are given in au, and $E^{\mathrm{NOCV}}$ are given in $\mathrm{kcal} \cdot \mathrm{mol}^{-1}$.

shielding contributions, defined in the ADF2016 program as $\mathrm{U} 1$ :

$$
\sigma^{\mathrm{pSO}}=\sigma_{2 \mathrm{c}}^{\mathrm{U} 1}-\sigma_{1 \mathrm{c}}^{\mathrm{U} 1}
$$

This approach was also used for the MO analysis of $\sigma^{\mathrm{pSO}}$. Note that for the light-atom NMR spectroscopy (e.g., ${ }^{1} \mathrm{H},{ }^{13} \mathrm{C}$, or $\left.{ }^{15} \mathrm{~N}\right), \sigma^{\mathrm{pSO}}$ contributes directly to the experimental NMR chemical shift because $\sigma^{\mathrm{pSO}}$ is negligible (below $1 \mathrm{ppm}$ ) in typical reference compounds which do not contain heavy elements.

Four-Component Nuclear Magnetic Shielding Constants. The GIAO NMR shielding constants were calculated using the full four-component relativistic Dirac-Kohn-Sham (DKS) formalism based on the Dirac-Coulomb Hamiltonian and restricted magnetically balanced basis for the small component, ${ }^{69,70}$ as implemented in the developer version of the ReSpect 4.0.0 code. $^{71}$ The PBE0 functional, ${ }^{38,72}$ the uncontracted Dyall's valence triple- $\zeta$ basis set for metals, and uncontracted Jensen's pc2 basis sets for light atoms were used. $^{73-75}$ The same basis-set setup provided very good results in our previous studies. $9,76,77$

The spin-orbit contribution to the paramagnetic NMR shielding term, denoted as $\sigma_{4 \mathrm{c}}^{\mathrm{pSO}}$ in this work, was calculated as the difference between the full $4 \mathrm{c}$ (DKS) and SO-scaled (omitting SO integrals) ${ }^{78}$ DKS paramagnetic shielding contributions, defined in ReSpect as P1_E:

$$
\sigma_{4 \mathrm{c}}^{\mathrm{pSO}}=\sigma_{4 \mathrm{c}}^{\mathrm{P} 1 \_\mathrm{E}}-\sigma_{\mathrm{SO}-\text { scaled }}^{\mathrm{P} 1 \mathrm{E}}
$$

This approach was also used for the MO analysis of $\sigma_{4 c}^{\mathrm{pSO}}$ (see the Supporting Information). Very good agreement between the corresponding $2 \mathrm{c}$ and $4 \mathrm{c}$ paramagnetic NMR shielding constants (for comparisons of $\sigma_{1 \mathrm{c}}^{\mathrm{pSO}}, \sigma_{2 \mathrm{c}}^{\mathrm{pSO}}$, and $\sigma_{4 \mathrm{c}}^{\mathrm{pSO}}$, see Figures S2 and S3 as well as Tables S3 and S4 in the Supporting Information) justifies the use of analysis performed at the $2 \mathrm{c}$ level.

Analysis of the SO/FC Mechanism Using Third-Order Perturbation Theory. The calculation and analysis of spinorbit contributions to the NMR shielding constants were implemented into the ReSpect program package in the framework of both Hartree-Fock (HF) and Kohn-Sham (DFT) levels of theory. For this purpose, the third-order response theory of ref 79 was modified for the static (frequency-free) case. In the case of HF theory the implementation is identical to that in refs 17 and 80 where the notation SO/FC and SO/SD used in this work corresponds to FC-I and SD-I terms in the former work and so-called SO term in the latter. Finally, we note that the second-order kernel contributions (third-order derivative of the DFT exchangecorrelation functional) have been omitted in the present DFT implementation. This approximation does not influence the qualitative analysis performed in this work; however, the missing kernel contribution will be implemented in the near future, as it is necessary to obtain more quantitative insights.

\section{RESULTS AND DISCUSSION}

As described in the Introduction, the SO-induced effects on the ${ }^{13} \mathrm{C}$ and ${ }^{15} \mathrm{~N}$ NMR shielding constants have recently been linked to the type of orbital magnetic couplings $\left(5 d \leftrightarrow 5 d^{*}\right.$ vs $\left.6 p \leftrightarrow 6 p^{*}\right)$ and covalence of the HA-LA bonding. ${ }^{7,8,25,26}$ Herein we perform a systematic investigation of the $\sigma^{\mathrm{p}}$ and $\sigma^{\mathrm{SO}}$ contributions for model transition-metal complexes (see Figure 1). The ultimate goal of this work is to understand how the changes in electronic structure (electron configuration of the central metal atom and character of the $\mathrm{M}-\mathrm{L}$ bonding) affect the NMR shielding constants of the light atoms L. We focus on the spin-orbit-induced changes in the molecular orbitals, in particular those altering the $\mathrm{M}-\mathrm{L}$ bond.

4.1. Au(I) Compounds: Effect of the Trans Substituent (X) on the Character of the M-L Bond and Ligand SpinOrbit NMR Shielding. 4.1.1. Spin-Orbit Effects on the Ligand NMR Shielding Constants - General Trends and Structural Trans Effect along the Au(I) Series. To get a detailed understanding of the relationships between the ligand NMR chemical shifts and the nature of M-L bonding we first analyze simple linear $\mathrm{Au}(\mathrm{I})$ complexes of pyridine with various substituents $(\mathrm{X})$ in the trans position to the NMR spectator atom L (Figure 1). In Table 1, compounds $\mathbf{1 a - 1 k}$ are ordered according to their structural trans effect. This arrangement nicely reflects the magnitude of $\sigma^{\mathrm{SO}}$ and the $\mathrm{M}-\mathrm{L}$ distance. ${ }^{23}$ The strength of the trans ligand (its propensity to electron sharing) alters the character of $\mathrm{M}-\mathrm{L}$ bonding which is sensitively reflected in $\sigma^{\mathrm{p}}$ and $\sigma^{\mathrm{SO}}$ of the spectator ligand 
atom L (Table S5). ${ }^{7,8,27}$ This enables a detailed analysis of the correlation between the $\sigma^{\mathrm{SO}}(\mathrm{L})$ and the electronic structure in given complexes. As an example, the orientation of principal axes of the ${ }^{15} \mathrm{~N}$ NMR shielding tensor for compound $\mathbf{1 a}$ is shown in Figure 3.

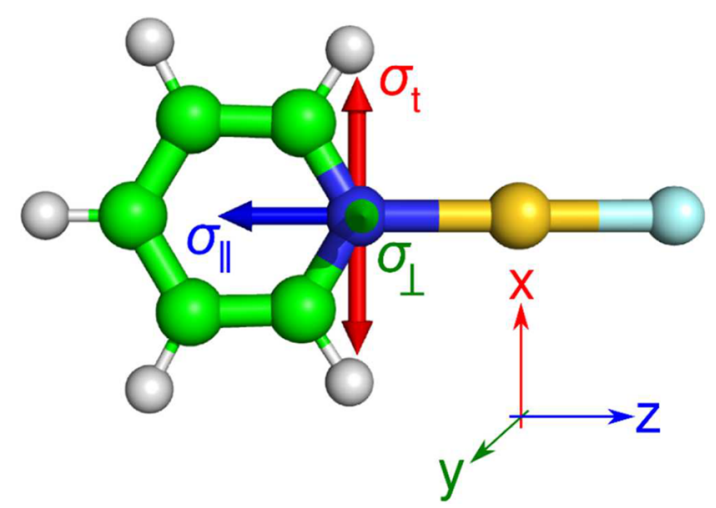

Figure 3. Orientation of principal axes of the ${ }^{15} \mathrm{~N}$ NMR shielding tensor, $\sigma(\mathrm{L})$, for compound 1a. The parallel component $\left(\sigma_{\|}\right.$in blue) coincides with the $z$-axis of the coordination system, the tangential component $\left(\sigma_{\mathrm{t}}\right.$ in red) lies along the $x$-axis, and the perpendicular component $\left(\sigma_{\perp}\right.$ in green $)$ lies along the direction of the $y$-axis. ${ }^{81}$

As demonstrated previously, the $\sigma^{\mathrm{SO}}(\mathrm{L})$ correlates exponentially with the interatomic distance ${ }^{18,82}$ and linearly with the covalence of the $\mathrm{M}-\mathrm{L}$ bond, which can be characterized, for example, by the QTAIM delocalization index. ${ }^{8}$ Both the M-L distance and the covalence of the $\mathrm{M}-\mathrm{L}$ bond are very effectively altered by the trans ligand $\mathrm{X}$ (see Table 1). To demonstrate this phenomenon, the relationships between the $\sigma^{\mathrm{SO}}\left({ }^{15} \mathrm{~N}\right)$ and the $\mathrm{Au}-\mathrm{N}$ distance, ${ }^{18,82} \mathrm{DI}(\mathrm{Au} \leftrightarrow \mathrm{N}),{ }^{8} \mathrm{DI}(\mathrm{Au} \leftrightarrow$
$\mathrm{N}) / r_{\mathrm{Au}-\mathrm{N}}{ }^{83,84}$ and $\mathrm{DI}(\mathrm{Au} \leftrightarrow \mathrm{N}) * \chi_{\mathrm{DM}}-\mathrm{DI}$ multiplied by trans substituent atomic or group electronegativity, based on Datta ${ }^{85}$ and Mullay ${ }^{86,87}\left(\chi_{\text {DM }}\right)$ - are shown in Figure 4. A good correlation for the DI scaled by electronegativity of the trans substituent (Figure $4 \mathrm{~d}$ ) relates to the polarization of shared HA-orbital by trans $\mathrm{X}$, which scales with electronegativity of $\mathrm{X}$. This has in turn a direct influence on the $\sigma^{S \mathrm{O}}\left({ }^{15} \mathrm{~N}\right)$, as discussed in the Introduction. Note also similar slopes for halogen and chalcogen series in Figure $4 \mathrm{c}$ (in contrast to pnictogen series). This indicates that the electron lone pairs (LPs) on the trans $\mathrm{X}$ and $\pi$-type $\mathrm{M}-\mathrm{L}$ bonding also influence the $\sigma^{\mathrm{SO}}(\mathrm{L})$.

4.1.2. Structural Trans Effect on the Character of the Au$N$ Bond - the Localized MO Picture. To analyze the effect of the trans $\mathrm{X}$ substituent on the character of the $\mathrm{Au}-\mathrm{N}$ bond we performed the EDA-NOCV analysis. Energy decomposition analysis provides classical electrostatic $\left(E_{\mathrm{Els}}\right)$ and orbital $\left(E_{\mathrm{Orb}}\right)$ terms which can be used for estimating the role of bond polarity and orbital interactions, respectively. The individual EDA contributions to interaction energy, $E_{\text {Int }}$ for $\mathrm{Au}-\mathrm{X}$ and $\mathrm{Au}-\mathrm{N}$ bonds in compounds $\mathbf{1 a}-\mathbf{1 k}$ are summarized in Table $S 6$ in the Supporting Information. The important role of $E_{\mathrm{Orb}}$ for the $\mathrm{Au}-\mathrm{N}$ bond is highlighted in Table 1. To demonstrate the direct link between the character of the $\mathrm{Au}-\mathrm{N}$ bond and $\sigma^{\mathrm{SO}}$, correlations between $\sigma^{\mathrm{SO}}\left({ }^{15} \mathrm{~N}\right)$ and $E_{\text {Int }}(\mathrm{Au}-\mathrm{N})$ as well as between $\sigma^{\mathrm{SO}}\left({ }^{15} \mathrm{~N}\right)$ and $E_{\mathrm{Orb}}(\mathrm{Au}-\mathrm{N})$ are shown in Figure 5. Similar to the $\mathrm{DI}(\mathrm{Au} \leftrightarrow \mathrm{N})$ in Figure $4, E_{\mathrm{Orb}}$ of $\mathrm{Au}-\mathrm{N}$ bond scales with the polarity of the trans $\mathrm{X}$. $E_{\mathrm{Orb}}$ can be further decomposed into energetic contributions from individual NOCV channels (occupied-vacant orbital pairs), which provide a more detailed view to the bonding situation. The contributions of the first four NOCV channels $\left(\mathrm{NOCV}_{1}-\right.$ $\left.\mathrm{NOCV}_{4}\right)$ to $E_{\mathrm{Orb}}$ are summarized in Table 1 and discussed on
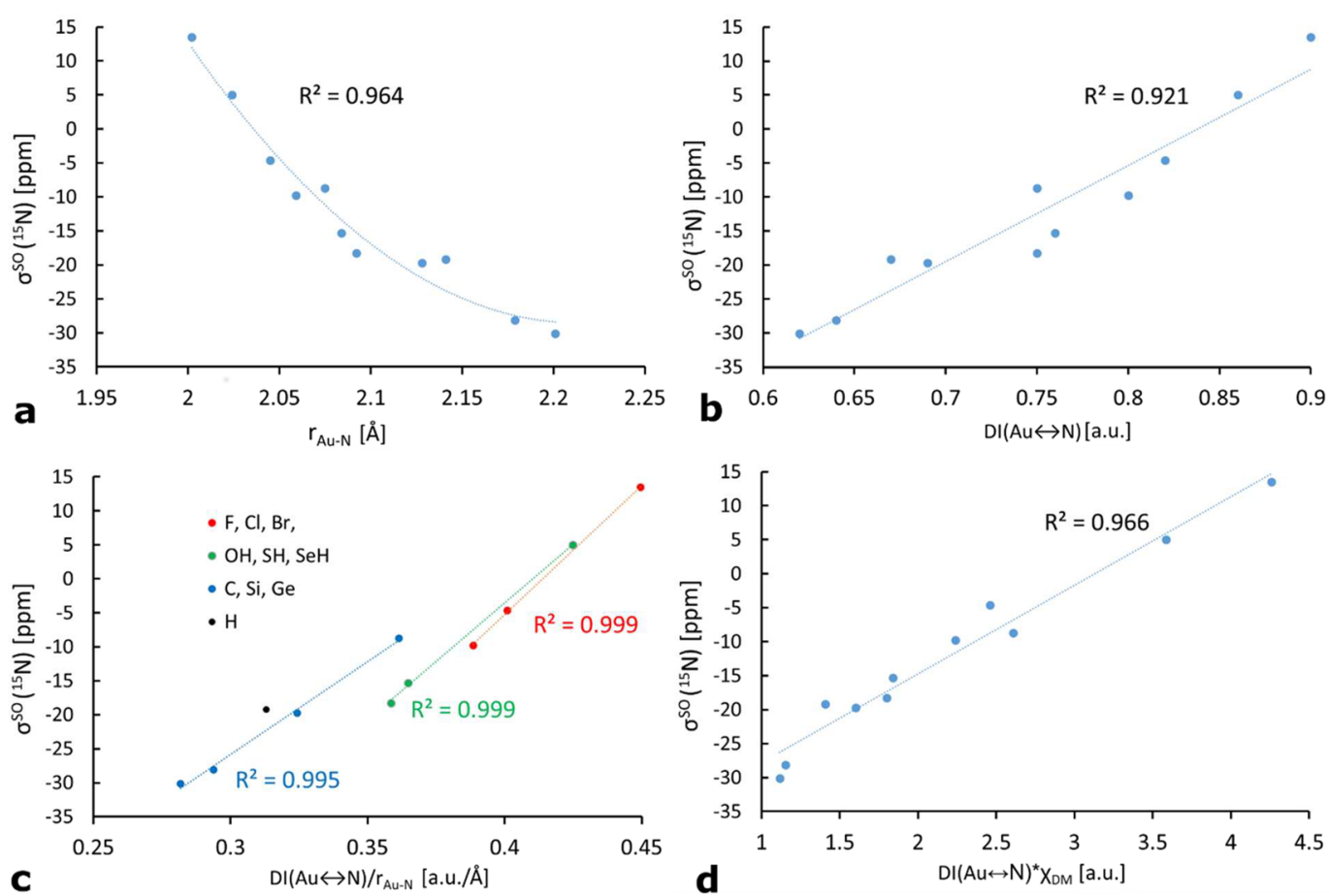

Figure 4. Correlation between $\sigma^{\mathrm{SO}}\left({ }^{15} \mathrm{~N}\right)$ and a) the Au-N distance $\left.\left.\left(\sigma^{\mathrm{SO}}=a \cdot r_{\mathrm{Au}-\mathrm{N}}^{2}-b \cdot r_{\mathrm{Au}-\mathrm{N}}+c\right),{ }^{82} \mathbf{b}\right) \mathrm{DI}(\mathrm{Au} \leftrightarrow \mathrm{N}), \mathbf{c}\right) \mathrm{DI}(\mathrm{Au} \leftrightarrow \mathrm{N}) / r_{\mathrm{Au}-\mathrm{N}}$ separately for halogen (red, Group 17), chalcogen (green, Group 16), pnictogen (blue, Group 15), and hydrogen (black) trans substituents X, and d) DI(Au↔ $\mathrm{N}) * \chi_{\mathrm{DM}}$ for $1 \mathrm{a}-1 \mathrm{k}$. 

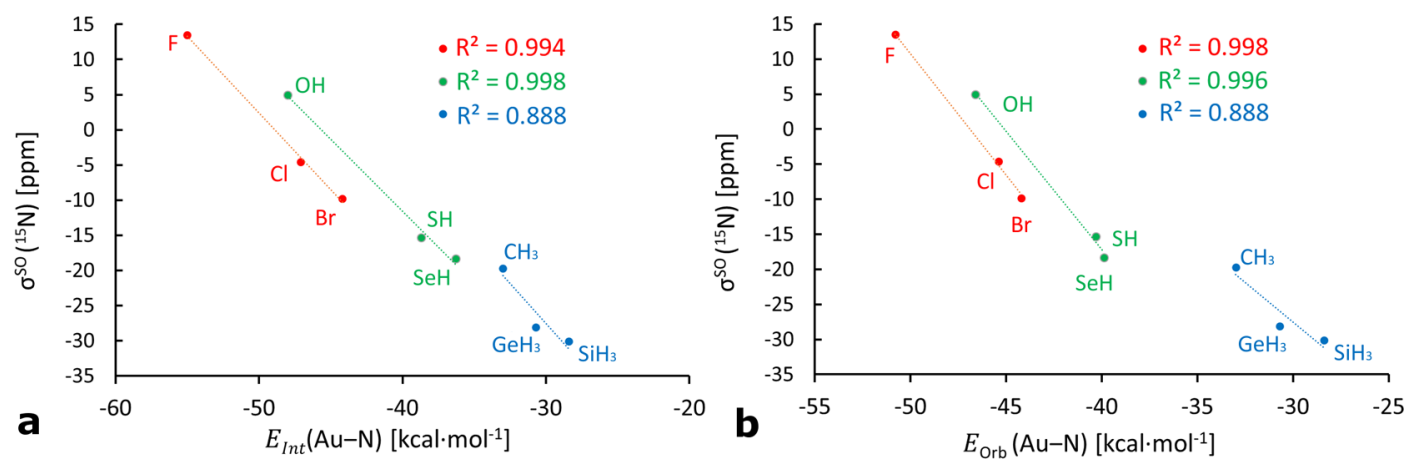

Figure 5. Correlation between $\sigma^{\mathrm{SO}}(\mathrm{N})$ and $\left.\mathbf{a}\right) E_{\text {Int }}(\mathrm{Au}-\mathrm{N})$ and $\left.\mathbf{b}\right) E_{\mathrm{Orb}}(\mathrm{Au}-\mathrm{N})$ for $\mathrm{Au}(\mathrm{I})$ complexes 1a-1k.

the example of isoelectronic complexes with $\mathrm{F}(\mathbf{1 a})$ and $\mathrm{CH}_{3}$ (1i) ligands, see Figure 6.

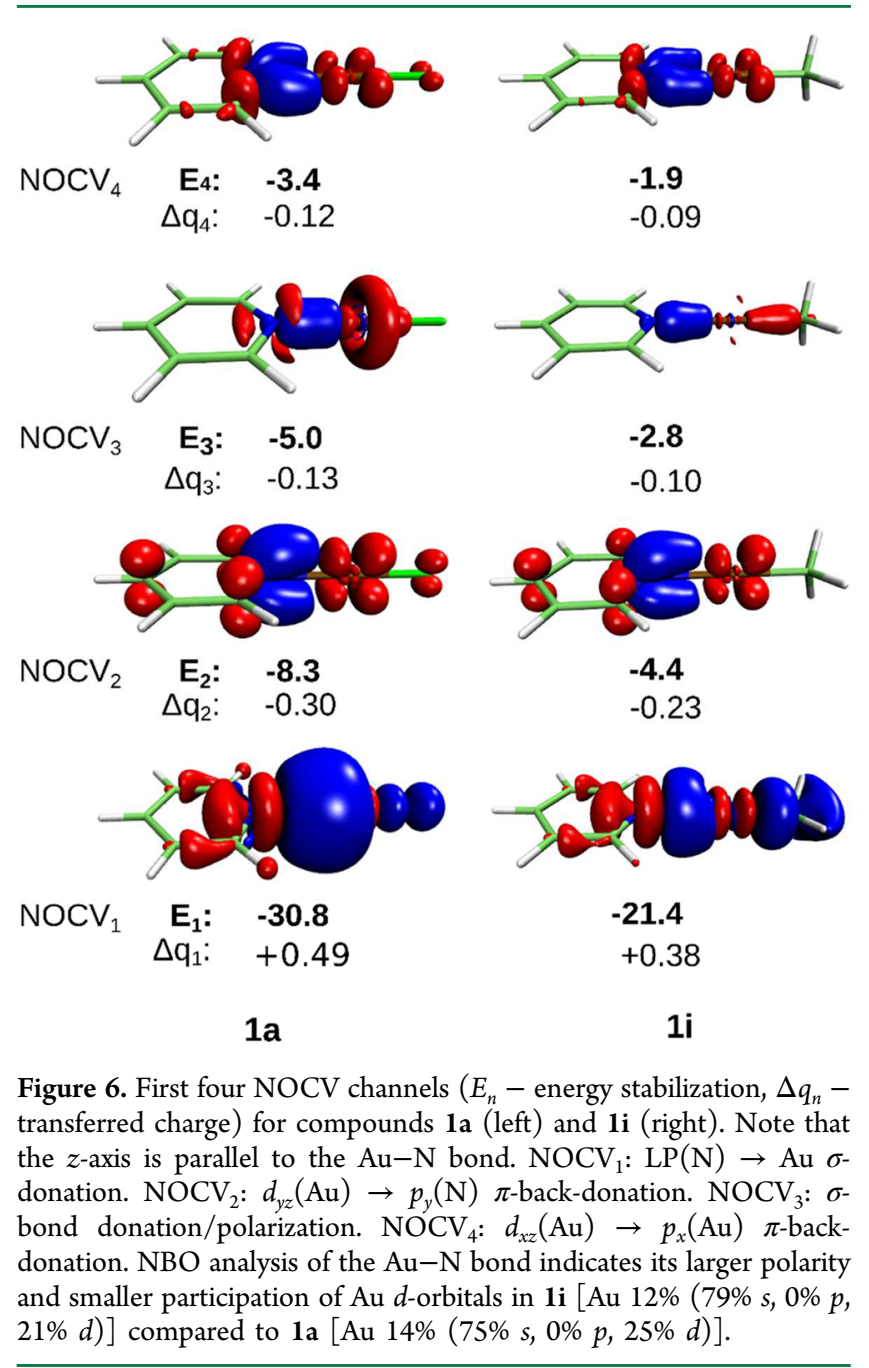

The first channel, $\mathrm{NOCV}_{1}$, corresponds to the donation of the nitrogen LP (with $2 p_{z} \mathrm{AO}$ character) to the vacant orbital at the gold atom (charge transfer from the ligand toward the $\mathrm{Au}-$ $\mathrm{X}$ fragment in the $\sigma$-space). The corresponding $E_{1}$ contributions to the $\mathrm{M}-\mathrm{L}$ bond energies vary from -30.8 to $-21.4 \mathrm{kcal}$. mol ${ }^{-1}$ for $\mathrm{F}$ (1a) and $\mathrm{CH}_{3}$ (1i) trans ligands $\mathrm{X}$, respectively. Considerably larger $E_{1}$ highlights a significantly stronger $\mathrm{Au}-\mathrm{N}$ $\sigma$-bonding character in 1a. In parallel to the stronger $\sigma$-bonding, the $\pi$-back bonding (charge shift from metal toward pyridine moiety in the $\pi$-space $)^{88}$ realized by $5 d_{y z}$ (channel 2) and $5 d_{x z}$ (channel 4) donation to nitrogen $2 p$ orbitals is also more pronounced in 1a. This is partly related to the $\pi$-space donation capacity of the trans ligand $\mathrm{F}$ which enables formation of the $\pi$ conjugated system; note the fluorine $\pi$-type orbitals in $\mathrm{NOCV}_{2}$ and $\mathrm{NOCV}_{4}$. The back-bonding is accompanied by the somewhat shorter interatomic $\mathrm{Au}-\mathrm{N}$ distance in 1a, which allows for a more efficient overlap between the $M(\mathrm{Au})$ and $\mathrm{L}$ (N) orbitals forming the $\pi$-bond. Notice also significant concentration of charge at $\mathrm{Au}$ for $1 \mathrm{a}$ in $\mathrm{NOCV}_{1}$ (bottom left, the weak trans $\sigma$-bond). In contrast, charge-shift propagation to the trans ligand $\mathrm{X}$ via the strong trans $\sigma_{\mathrm{Au}-\mathrm{X}}$ bond is clearly visible from $\mathrm{NOCV}_{1}$ for $\mathbf{1 i}$ (bottom right).

Thus, in the case of weak trans $\mathrm{X}$, such as $\mathrm{F}$, the $\mathrm{M}-\mathrm{X}$ bond (here $\mathrm{Au}-\mathrm{F}$ in $\mathbf{1 a}$ ) is highly polar, which enables the formation of a more covalent $\mathrm{Au}-\mathrm{N}$ bond (cf. $r_{\mathrm{Au}-\mathrm{N}}, \mathrm{DI}$, and $E_{\mathrm{Int}}$ values in Table 1). On the contrary, the more covalently bonded trans methyl ligand induces weakening of the $\mathrm{Au}-\mathrm{N}$ bond in 1i. This is paralleled by the destabilization of the particular MOs, which in turn influence the ${ }^{15} \mathrm{~N}$ NMR shielding constant, see below.

4.1.3. Electronic Structure vs Ligand NMR Shielding Constants: The MO Picture. To understand how the ligand NMR shielding constants relate to the electronic structure, we performed Kohn-Sham molecular orbital (MO) analysis for isoelectronic systems $\mathbf{1 a}$ and $\mathbf{1} \mathbf{i}$, as they have opposite spinorbit contributions to the ${ }^{15} \mathrm{~N}$ NMR shielding constants $(+13.3$ ppm for 1a vs $-19.6 \mathrm{ppm}$ for $\mathbf{1 i}$, see Table 1). The frontier MO-energy diagrams for $\mathbf{1 a}$ and $\mathbf{1 i}$ along with $\mathrm{MO}$ contributions to the paramagnetic NMR shielding constants $\left(\sigma^{\mathrm{p}}\right)$ calculated at the 1c PBE0 level are shown in Figure 7 (for comparisons of $1 \mathrm{c}$ and $2 \mathrm{c}$ calculations at the PBE0 level, see Figure S4 and Figure S5 in the Supporting Information).

Analysis of $\sigma_{M-L}$-Bonding Contributions to $\sigma^{p}(L)$ at the Scalar-Relativistic 1c Level. There are two types of occupied $\sigma$ bonding MOs with significant contributions to $\sigma^{\mathrm{p}}(\mathrm{N})$ shown in Figure 7: $\sigma_{\mathrm{N}-\mathrm{C}}\left(\mathrm{MO55}\right.$ for 1a, MO54 for 1i) and $\sigma_{\mathrm{Au}-\mathrm{N}}(\mathrm{MO} 54$ for 1a, MO55 for 1i). They are both magnetically coupled to the vacant $\pi$-type $\mathrm{MO}^{*} \mathrm{~s}$ with sizable nitrogen $2 p_{y}$ AOs character. ${ }^{5,35}$ The schematic representation of the $\sigma_{\mathrm{Au}-\mathrm{N}} \leftrightarrow \pi^{*}$ coupling is shown as the Ramsey-type paramagnetic contribution in Figure 2a. As the trans substituent $\mathrm{X}$ efficiently alters the energy of the $\mathrm{Au}-\mathrm{N}$ bond, the role of the $\sigma_{\mathrm{Au}-\mathrm{N}}$-type orbitals in $\sigma^{\mathrm{p}}$ contributions varies significantly in the series of compounds. The $\sigma_{\mathrm{N}-\mathrm{C}}$-type orbitals are notably less affected by the substituent, see Figure 7.

The weakening of the $\mathrm{Au}-\mathrm{N}$ bond in $\mathbf{1 i}$ (the strong trans $\mathrm{Au}-\mathrm{CH}_{3}$ bond) relative to that in 1a can clearly be observed in the 1c Kohn-Sham MO diagram. This destabilizing effect of 


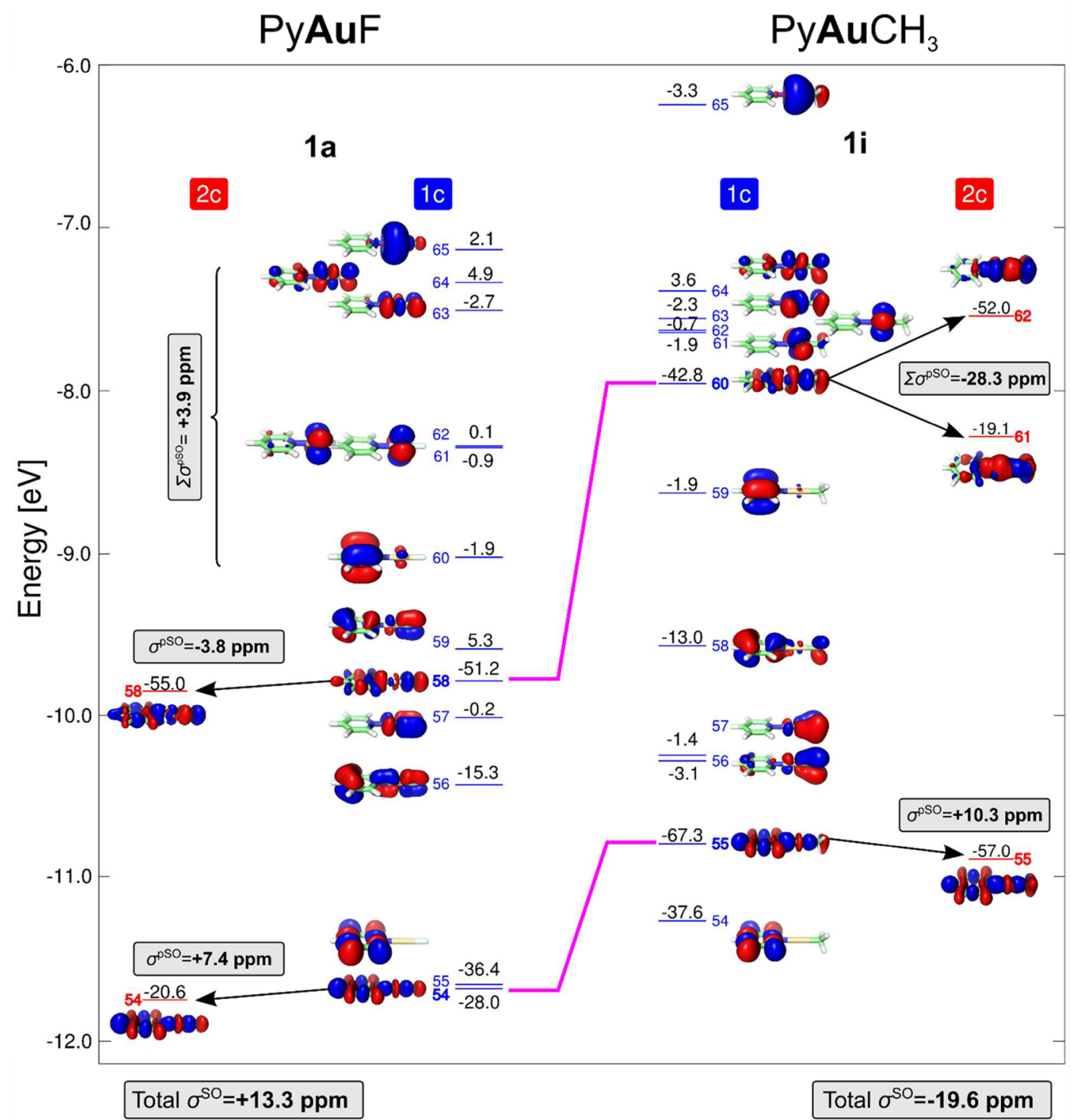

Figure 7. Energy diagram and orbital contributions to $\sigma^{p}$ from the frontier occupied Kohn-Sham MOs as obtained from 1c calculations (in blue, inner columns) for compound $1 \mathrm{a}$ (left) and $\mathbf{1 i}$ (right). The main substituent-induced changes in the $\sigma_{\mathrm{Au}-\mathrm{N}^{-}}$-space are highlighted by two magenta lines, and effects of the SO coupling on these selected orbitals are shown by arrows (2c levels in red, outer columns). The important SO-active MOs are highlighted in bold, and total $\sigma^{\text {SO }}$ values are given at the bottom.

the trans methyl ligand in $\mathbf{1 i}$ is highlighted by the magenta lines between the corresponding $\sigma_{\mathrm{Au}-\mathrm{N}}$ orbitals, namely MO54 (1a) - MO55 (1i) and MO58 (1a) - MO60 (1i). The substituentinduced energy destabilization (manifested by decreasing the $\Delta E_{\mathrm{MO}-\mathrm{MO}} *$ denominator in eq 4 ), accompanied by a larger $\mathrm{N}$ $2 p$ character of MO55 in $1 \mathbf{i}$ as compared to MO54 in 1a, is responsible for a larger deshielding contribution of $\sigma_{\mathrm{Au}-\mathrm{N}}$ to $\sigma^{\mathrm{p}}$ (N) (-67.3 ppm for 1i vs $-28.0 \mathrm{ppm}$ for $1 \mathrm{a})$.

The situation is a bit more complicated for the higher-lying $\sigma$-type $\mathrm{Au}-\mathrm{N}$ orbital (MO58 in 1a, MO60 in 1i). Its larger substituent-induced energy destabilization of about $+1.86 \mathrm{eV}$ $\left(E_{\mathrm{MO58}(1 \mathrm{1})}=-9.82 \mathrm{eV}\right.$ vs $\left.E_{\mathrm{MO60}(1 i)}=-7.96 \mathrm{eV}\right)$ as well as conserved nitrogen $2 p_{z}$ character should intuitively lead to larger deshielding in 1i. The observed opposite trend $(-51.2$ ppm for 1a vs $-42.8 \mathrm{ppm}$ for 1i) can be rationalized by a notable increase in the Au $5 d_{z}{ }^{2}$ character from $2 \%$ in MO58 of 1a to $28 \%$ in MO60 of $\mathbf{1 i}$ (for total Au $d$ AO contributions, see Table S7). The observed large gold character in MO60 together with its energetic proximity to $\pi$-type orbitals (MO61-MO64) are the essence for a particular sensitivity of MO60 to the spinorbit coupling and the SO-induced orbital mixing.

Analysis of $\sigma_{M-L}$-Bonding Contributions to $\sigma^{p}(L)$ at the Spin-Orbit Relativistic 2c Level. The MO58 in 1a has a rather small Au $5 d$ character and is affected by SO coupling only marginally, $\sigma_{\mathrm{MO} 88}^{\mathrm{pSO}}=-3.8 \mathrm{ppm}$ (see Figure 7 ). In contrast, its counterpart in 1i, MO60, is split by the SO coupling into MO61 and MO62, containing admixtures from nonbonding $\mathrm{Au}$ $5 d$ MOs (formally $\mathrm{Au}$ LPs) and $\pi_{\mathrm{Au}-\mathrm{X}}$-type MOs-MO61MO64. Note that such mixing of MOs with $\sigma$ - and $\pi$-symmetry is allowed only in the presence of SO coupling. ${ }^{12}$ The $\sigma / \pi$ mixing in $\mathbf{1 i}$ is the consequence of the above-mentioned destabilization of MO60 due to the strong trans effect bringing the frontier MOs of $\sigma$ - and $\pi$-symmetry closer to contact. The resulting two $2 \mathrm{c}$ MOs in $\mathbf{1 i}$ with significant $\sigma$-character are coupled more efficiently with the vacant-orbital space and are responsible for the large SO-induced deshielding contribution of about $-28.3 \mathrm{ppm}$. 
The second $\sigma_{\mathrm{Au}-\mathrm{N}}$ contribution, represented by MO54 in 1a and MO55 in 1i, is only weakly altered by the SO coupling. These MOs are slightly energetically stabilized at the $2 \mathrm{c}$ level $\left(\Delta E_{\mathrm{MO} 54}^{\mathrm{SO}}=-0.07 \mathrm{eV}, \Delta E_{\mathrm{MO} 55}^{\mathrm{SO}}=-0.1 \mathrm{eV}\right)$ and contribute less to the total paramagnetic deshielding, $\sigma_{\mathrm{MO} 58}^{\mathrm{pSO}}=+7.4 \mathrm{ppm}$ and $\sigma_{\mathrm{MO} 55}^{\mathrm{pSO}}=+10.3 \mathrm{ppm}$.

In summary, the $\sigma^{\mathrm{pSO}}$ contributions arising from the two above-mentioned $\sigma$-type MOs sum up to $\sigma^{\mathrm{pSO}}=+3.6 \mathrm{ppm}$ for 1a $\left(\sim 25 \%\right.$ of total $\left.\sigma^{\mathrm{SO}}=+13.3 \mathrm{ppm}\right)$ and $\sigma^{\mathrm{pSO}}=-18.0 \mathrm{ppm}$ for 1i $\left(\sim 90 \%\right.$ of total $\left.\sigma^{\mathrm{SO}}=-19.6 \mathrm{ppm}\right)$. Clearly, the sign of the $\sigma^{\text {pSO }}$ values parallels the total SO-induced shielding/deshielding effect.

Contributions from $\pi$-Type $M-L$ Bonding to $\sigma^{p}(L)$ in $1 a$. Similar to $\sigma$-bonding discussed above, the $\pi_{\mathrm{Au}-\mathrm{N}}$ back-bonding MOs are destabilized in $\mathbf{1 i}$ and play an even less important role in $\mathrm{Au}-\mathrm{N}$ bonding (cf. NOCV channels in Figure 6). The lesser $\mathrm{Au}-\mathrm{N}$ back-bonding efficiency in $\mathbf{1 i}$ (cf. $\pi$-bonding capability of trans fluorine atom in $\mathrm{NOCV}_{2}$ of $\mathbf{1 a}$ ) is linked to the weak stabilization of the occupied antibonding $\pi_{\mathrm{Au}-\mathrm{N}}$ orbitals in $\mathbf{1 i}$ (upper lying $\mathrm{Au} 5 d_{x z}$-based and Au $5 d_{y z}$-based MO63 and MO64) as compared to those in 1a. Thus, small SO shielding contributions from these $\pi$-type MOs in 1a of about $\sigma_{\mathrm{MO} 61-64}^{\mathrm{SO}}=$ +3.9 ppm vanish in 1i. The $\pi_{\mathrm{M}-\mathrm{L}}$-type MOs can play a more significant or even dominant role in determining the sign of the total $\sigma^{\mathrm{pSO}}$ in other transition-metal complexes, in particular those with $\pi$-donors in the trans position such as compound $\mathbf{4 a}$ discussed in Section 4.3.

4.2. Au(III) Complexes: Role of Metal Oxidation State and Atomic Charge. The effects of the heavy-atom oxidation state on the $\sigma^{\mathrm{SO}}(\mathrm{L})$ have already been reported for compounds containing p-block elements. ${ }^{24,76}$ Here we focus on the chargeneutral $\mathrm{Au}(\mathrm{I})$ and $\mathrm{Au}(\mathrm{III})$ complexes (for structures, see Figure 1). The calculated $\sigma^{\mathrm{SO}}\left({ }^{15} \mathrm{~N}\right)$ values and $E_{\mathrm{Orb}}$ for selected PyAu ${ }^{\mathrm{III}} \mathrm{Cl}_{2} \mathrm{X}$ complexes 2 are summarized in Table 2 (for full

Table 2. Calculated Au-N Bond Length $\left(r_{\mathrm{Au}-\mathrm{N}}\right), \sigma^{\mathrm{SO}}\left({ }^{15} \mathrm{~N}\right),{ }^{a}$ Interaction Energy $\left(E_{\mathrm{Int}}^{\mathrm{Au}-\mathrm{N}}\right)$, and Orbital Contribution to the Interaction Energy $\left(E_{\mathrm{Orb}}^{\mathrm{Au}-\mathrm{N}}\right)^{b}$ for the $\mathrm{Au}-\mathrm{N}$ Bond in Selected $\mathrm{PyAu}^{\mathrm{III}} \mathrm{Cl}_{2} \mathrm{X}$ Complexes $2^{\mathrm{c}}$

\begin{tabular}{ccccc} 
compd - trans X & $r_{\mathrm{Au}-\mathrm{N}}$ & $\sigma^{\mathrm{SO}}\left({ }^{15} \mathrm{~N}\right)^{a}$ & \multicolumn{1}{c}{$E_{\mathrm{Int}}^{\mathrm{Au}-\mathrm{N}}$} & $E_{\mathrm{Orb}}^{\mathrm{Au}-\mathrm{N}}$ \\
$\mathbf{2 a}-\mathrm{F}$ & 2.020 & +15.3 & -66.0 & -78.2 \\
$\mathbf{2 e}-\mathrm{CN}$ & 2.104 & +5.3 & -50.1 & -60.1 \\
$\mathbf{2 h}-\mathrm{H}$ & 2.207 & -3.6 & -35.4 & -40.5 \\
$\mathbf{2} \mathbf{i}-\mathrm{CH}_{3}$ & 2.213 & -9.4 & -31.2 & -39.3 \\
$\mathbf{2 k}-\mathrm{SiH}_{3}$ & 2.306 & -10.9 & -23.8 & -30.5
\end{tabular}

${ }^{a}$ For full $\sigma^{\mathrm{SO}}$ tensors, see the Supporting Information. ${ }^{b}$ For the definition of $E_{\mathrm{Orb}}$ and EDA-NOCV channels, see Methods: Section 3.2. ${ }^{c}$ Bond lengths are given in $\AA, \sigma^{S O}\left({ }^{15} \mathrm{~N}\right)$ are given in ppm, and $E^{\mathrm{NOCV}}$ are given in $\mathrm{kcal} \cdot \mathrm{mol}^{-1}$.

data sets, see Tables S8 and S9). The increasing formal positive charge on gold as going from $\mathrm{Au}(\mathrm{I})$ in $\mathbf{1}$ to $\mathrm{Au}(\mathrm{III})$ in $\mathbf{2}$ is compensated for by two additional chloride ligands, whose binding alters the energy and composition of the SO-active MOs. For compound $\mathbf{2 a}$, the $\mathrm{Au}-\mathrm{N}$ bonding and shielding characteristics are similar to those for $1 \mathrm{a}-\mathrm{a}$ strong $\mathrm{M}-\mathrm{L}$ bond with the low-lying Au $d_{z}{ }^{2}$-based $\mathrm{MO}$ and total $\sigma^{\mathrm{pSO}}(+13.3 \mathrm{ppm}$ for $\mathbf{1 a}$ vs $+15.3 \mathrm{ppm}$ for $\mathbf{2 a}$ ). In contrast, compounds $\mathbf{1 i}$ and $2 \mathbf{i}$ behave somewhat differently. The destabilized MO60 in linear geometry of $\mathbf{1 i}$ has its counterpart in $\sigma_{\mathrm{Au}-\mathrm{N}}$ in $2 \mathbf{i}$ significantly stabilized by the different ligand field in square-planar geometry and the higher gold oxidation state (see Figure S6). This results in somewhat lower sensitivity of this $\sigma_{\mathrm{Au}-\mathrm{N}}$ in $2 \mathbf{i}$ to $\mathrm{SO}$ effects thus diminishing the overall SO deshielding (total $\sigma^{\mathrm{SO}}=-19.6$ ppm for $1 \mathbf{i}$ vs $\sigma^{\mathrm{SO}}=-9.4 \mathrm{ppm}$ for $2 \mathbf{i}$ ). Note also the substituent trends in $E_{\mathrm{Int}}$ and $E_{\mathrm{Orb}}$ in Table 2 paralleling those observed for compounds 1 .

4.3. Effect of the Central Metal Atom on the $\sigma^{\mathrm{SO}}(\mathrm{L})$ and the Character of the $\mathrm{M}-\mathrm{L}$ Bonding - Comparison of $\mathrm{Au}$ (I) Complexes with $\mathrm{Hg}$ (II) and $\mathrm{Pt}$ (II) Compounds. As we demonstrated in previous chapters on $\mathbf{1 a}$ and $\mathbf{1 i}$ complexes, the character of $\mathrm{Au}-\mathrm{N}$ bonding is reflected in $\sigma^{\mathrm{pSO}}$ of the nitrogen atom of the pyridine ligand $\mathrm{L}$. The $\sigma^{\mathrm{pSO}}$ has a positive sign in 1a (shielding effect), as typically observed for the transition-metal complexes with a partially filled $d$-shell (e.g., platinum or iridium), ${ }^{7,27}$ whereas $\sigma^{\mathrm{pSO}}$ is negative in 1i (deshielding effect), which is common in Group 12 (e.g., mercury) $)^{89,90}$ and early $p$-block (thallium, lead) ${ }^{76,77}$ compounds. Therefore, we analyzed a series of $\mathrm{Hg}$ (II) and $\mathrm{Pt}(\mathrm{II})$ compounds to investigate and reveal the origin of the SOinduced (de)shielding effects. The structure of these complexes is shown in Figure 1, and selected NMR data and bonding characteristics are summarized in Table 3 (for full data sets, see

Table 3. Calculated $\mathrm{M}-\mathrm{L}$ Bond Length and $\sigma^{\mathrm{SO}}(\mathrm{L})$ for Selected $\mathrm{PhHg}^{\mathrm{II} X}$ Complexes 3 and $\mathrm{PyPt}{ }^{\mathrm{II}} \mathrm{Cl}\left(\mathrm{NH}_{3}\right) \mathrm{X}$ Complexes $4^{a}$

\begin{tabular}{|c|c|c|c|c|c|}
\hline \multicolumn{3}{|c|}{$\mathrm{PhHg}^{\mathrm{II}} \mathrm{X}$ complexes 3} & \multicolumn{3}{|c|}{$\mathrm{PyPt}^{\mathrm{II}} \mathrm{Cl}\left(\mathrm{NH}_{3}\right) \mathrm{X}$ complexes 4} \\
\hline & $\mathrm{M}-\mathrm{C}$ bond & $\sigma^{\mathrm{SO}}\left({ }^{13} \mathrm{C}\right)$ & & $\mathrm{M}-\mathrm{N}$ bond & $\sigma^{\mathrm{SO}}\left({ }^{15} \mathrm{~N}\right)$ \\
\hline $3 a-F$ & 2.026 & -2.4 & $4 a-F$ & 1.995 & +50.6 \\
\hline $3 e-C N$ & 2.048 & -14.1 & $4 e-C N$ & 2.097 & +16.1 \\
\hline $3 \mathbf{i}-\mathrm{CH}_{3}$ & 2.083 & -28.2 & $4 \mathrm{i}-\mathrm{CH}_{3}$ & 2.157 & +3.7 \\
\hline $3 \mathbf{k}-\mathrm{SiH}_{3}$ & 2.106 & -36.8 & $4 \mathbf{k}-\mathrm{SiH}_{3}$ & 2.262 & -7.6 \\
\hline
\end{tabular}

${ }^{a}$ Bond lengths are given in $\AA$, and $\sigma^{\mathrm{SO}}(\mathrm{L})$ are given in ppm.

Tables S10-S13 and Figures S7 and S8 in the Supporting Information). To conserve charge neutrality of $\mathrm{Hg}$ (II) compounds $3 \mathbf{a}-\mathbf{k}$, the substitution of the phenyl ligand for pyridine was performed. In the following, compound $3 \mathbf{k}$ with strong $\sigma^{\mathrm{SO}}$ deshielding of $-37 \mathrm{ppm}$ and compound $4 \mathrm{a}$ with strong $\sigma^{\mathrm{SO}}$ shielding of $+51 \mathrm{ppm}$ are analyzed and compared in detail. Data for the remaining systems can be found in the Supporting Information.

4.3.1. Electronic Structure and Ligand NMR Shielding Constant in $\mathrm{PhHg}^{\prime \prime} \mathrm{SiH}_{3}$ - Compound 3k. The significant role of $\sigma_{\mathrm{M}-\mathrm{L}}$-type $\mathrm{MOs}$ identified for the magnetic couplings in $\mathrm{Au}(\mathrm{I})$ compound $\mathbf{1 i}$ is even more pronounced in $\mathrm{Hg}(\mathrm{II})$ compound $3 \mathbf{k}$, Figure 8 . This is related to a larger involvement of formally vacant $\mathrm{Hg} 6 p$ orbitals in bonding and a reduced importance of the more compact $5 d$-shell of $\mathrm{Hg}$. In the following two subsections we discuss the role of $\sigma_{\mathrm{M}-\mathrm{L}}$-type MOs in $\sigma^{\mathrm{pSO}}$ and perform the analysis of the deshielding mechanism using third-order perturbation theory.

The Dominant Role of Occupied $\sigma$-Type $M-L$ Bonding MOs for $\sigma^{p S O}$. In $\mathrm{Hg}$ compound $3 \mathbf{k}$, the highest occupied MO69 of $\sigma_{\mathrm{M}-\mathrm{L}}$ character, composed of $30 \% \mathrm{C} 2 p_{z}, 6 \% \mathrm{C} 2 s$, and $9 \% \mathrm{Hg} 6 p_{z}$, is effectively coupled with the vacant-orbital space resulting in $\sigma_{1 \mathrm{c}}^{\mathrm{p}}=-57.9 \mathrm{ppm}$. This can be seen as the Ramsey-type paramagnetic $2 p_{z} \leftrightarrow 2 p_{y}$ coupling (Figure 2a). In contrast to the scalar-relativistic $\sigma_{1 \mathcal{c}}^{\mathrm{p}}$, the two-component contribution from MO69, $\sigma_{2 c}^{p}=-82.5 \mathrm{ppm}$, reveals a dominant role of this orbital in total $\sigma^{\mathrm{pSO}}$ deshielding $\left(\sigma_{\mathrm{MO} 69}^{\mathrm{pSO}}=-24.6\right.$ ppm of total $\sigma^{\mathrm{SO}}=-36.8 \mathrm{ppm}$ ), as indicated in Figure 8. In addition to MO69, $\sigma^{\mathrm{pSO}}$ also arises from the second occupied $\sigma$ - 


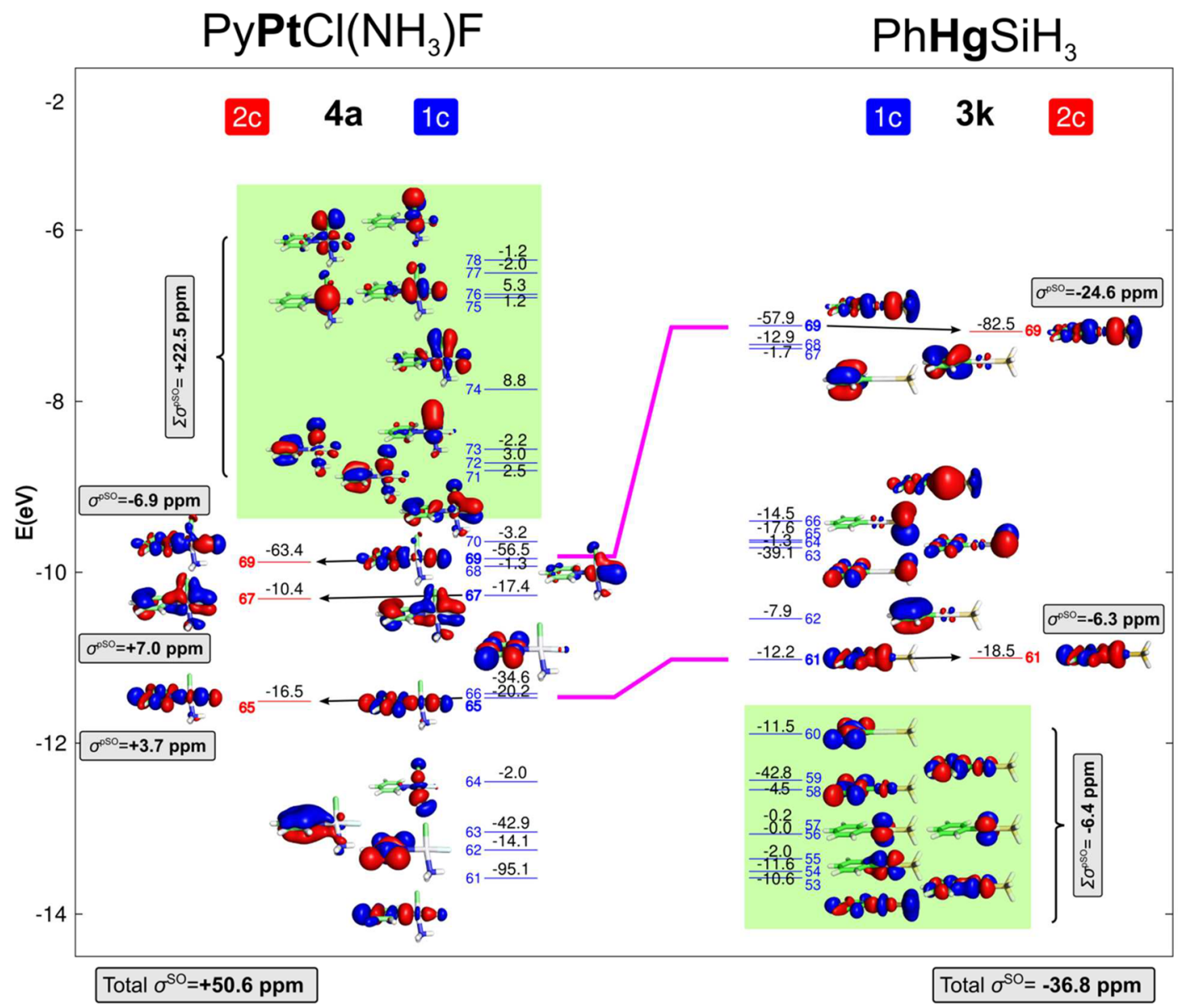

Figure 8. Energy diagram and orbital contributions to $\sigma^{\mathrm{p}}$ from the frontier occupied Kohn-Sham MOs as obtained from 1c calculations (in blue, inner columns) for $\mathrm{Pt}(\mathrm{II})$ compound $4 \mathrm{a}$ (left) and $\mathrm{Hg}(\mathrm{II})$ compound $3 \mathbf{k}$ (right). The main structure-induced changes in the $\sigma_{\mathrm{M}-\mathrm{L}^{-} \mathrm{space}}$ are highlighted by two magenta lines, and effects of the SO coupling on the selected orbitals are shown by arrows (2c levels in red, outer columns). The important SO-active MOs are highlighted in bold, and total $\sigma^{\text {sO }}$ values are given at the bottom. The significant stabilization of metal $5 d$-based orbitals (mainly $\pi_{\mathrm{M}-\mathrm{L}}$-type and LPs) in $3 \mathbf{k}$ compared to those in $\mathbf{4 a}$ is highlighted by the light-green background.

\section{PARAMAGNETIC}

$(1 \mathrm{c}, \mathrm{GIAO})$

a)

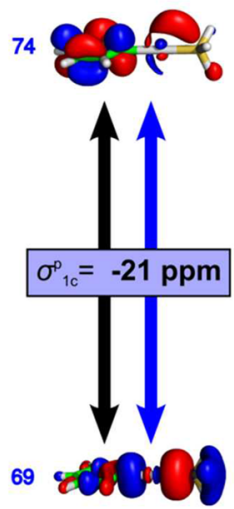

b)

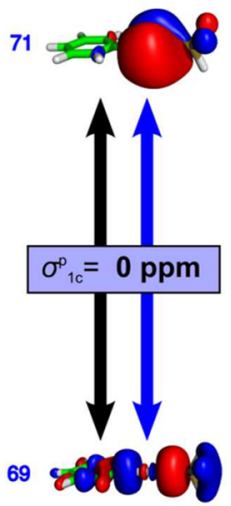

SPIN-ORBIT

(SO/FC $\triangle$, CGO)

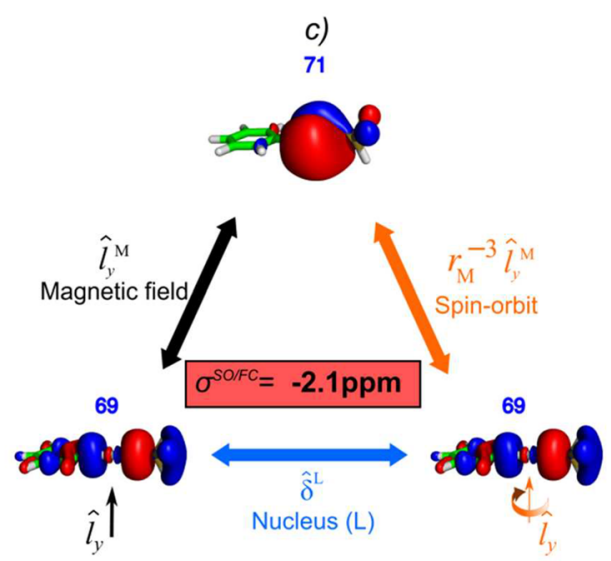

Figure 9. Visualization and analysis of MO magnetic couplings in $\mathrm{Hg}$ compound 3k: a) the "active" 1c Ramsey-type $\sigma_{\mathrm{M}-\mathrm{L}} \leftrightarrow \pi^{*}{ }_{\mathrm{M}-\mathrm{L}}$ coupling $\left(\hat{l}_{x}\right)$ leads to the deshielding $\sigma^{\mathrm{P}}\left({ }^{13} \mathrm{C}\right)$ effect. The involved MOs $69 \leftrightarrow 74^{*}$ are mainly composed of $2 p_{z} \leftrightarrow 2 p_{y}$ AOs of the ligand carbon (L); b) the "inactive" 1c Ramsey-type coupling MO69↔MO71*. This coupling is forbidden by symmetry. c) the deshielding SO contribution to $\sigma^{\mathrm{p}}\left({ }^{13} \mathrm{C}\right)$ involving the $\mathrm{SO} / \mathrm{FC}$ coupling mechanism MO69↔MO71*↔MO69.

bonding orbital MO61 $\left(\sigma_{\mathrm{MO} 61}^{\mathrm{pSO}}=-6.3 \mathrm{ppm}\right)$ and from the formally closed $\mathrm{Hg} 5 d$ shell $\left(\sum \sigma_{\mathrm{MO} 53-59}^{\mathrm{SO}}=-6.4 \mathrm{ppm}\right)$. In passing, note the significant structure-induced contraction and stabilization of the metal $d$-based orbitals in $3 \mathbf{k}$ compared to those in $\mathbf{4 a}-\mathbf{a}$ phenomenon highlighted by the light-green background in Figure 8 (for the 2c level, see Figure S7). 
PARAMAGNETIC

(1c, GIAO)

a)

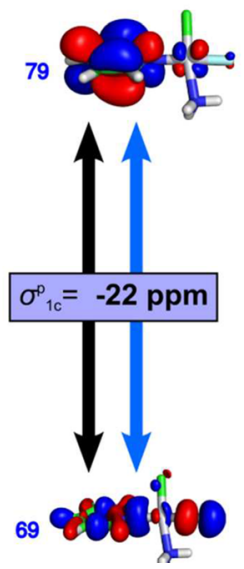

b)

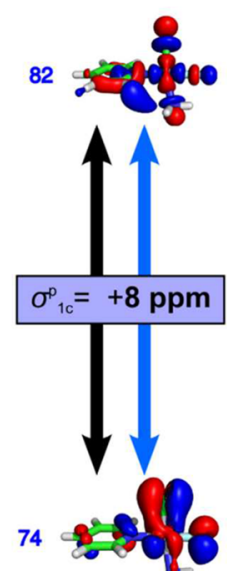

SPIN-ORBIT

$(\mathrm{SO} / \mathrm{FC}, \mathrm{CGO})$

c)

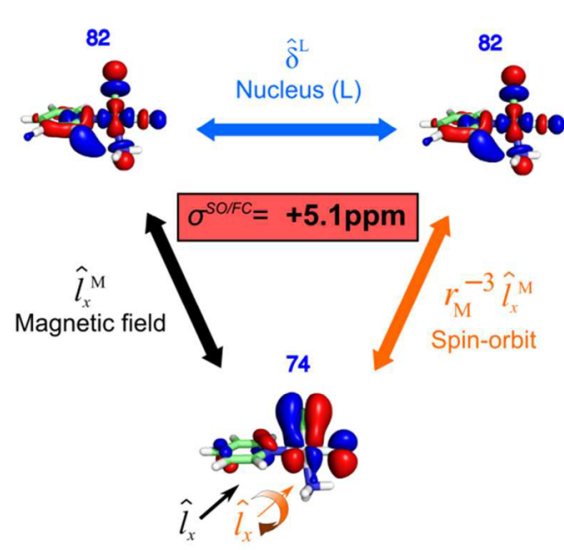

Figure 10. Visualization and analysis of MO magnetic couplings in Pt compound 4a: a) the classical 1c Ramsey-type $\sigma_{\mathrm{M}-\mathrm{L}} \leftrightarrow \pi^{*}{ }_{\mathrm{M}-\mathrm{L}}$ coupling $\left(\hat{l}_{x}\right)$ leads to the deshielding $\sigma^{\mathrm{P}}\left({ }^{15} \mathrm{~N}\right)$ effects. The involved MOs $69 \leftrightarrow 79^{*}$ are composed of $2 p_{z} \leftrightarrow 2 p_{y}$ AOs of the ligand nitrogen (L). b) the classical $1 \mathrm{c}$ Ramsey-type $\pi_{\mathrm{M}-\mathrm{L}} \leftrightarrow \sigma^{*}{ }_{\mathrm{M}-\mathrm{L}}$ coupling leads to the shielding $\sigma^{\mathrm{P}}\left({ }^{15} \mathrm{~N}\right)$. The involved MOs $74 \leftrightarrow 82^{*}$ are composed of $2 p_{y} \leftrightarrow 2 p_{z}$ AOs of the ligand

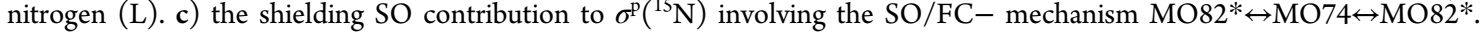

Summing up all three above-mentioned contributions, we arrive at $\sigma^{\mathrm{pSO}} \approx-36 \mathrm{ppm}$ which corresponds to $\sim 100 \%$ of the total $\sigma^{\mathrm{SO}}$, out of which $-30 \mathrm{ppm}(80 \%)$ originates from $\sigma$-bonding MOs (MO69 and MO61). This is in perfect agreement with the overall trend established for $\mathrm{Au}(\mathrm{I})$ complexes featuring different trans $\mathrm{X}$ substituents. To get a deeper insight into the origin of the deshielding mechanism arising from MO69 and propagation of the SO-induced spin density to atom L, we performed third-order perturbation $\mathrm{MO}$ analysis.

SO Contributions from Highest Occupied $M-L$ Bonding M069 to $\sigma^{p}(\mathrm{~L})$ : Analysis of Deshielding Fermi-Contact Mechanism $\left(\mathrm{SO}_{\mathrm{FC}}{ }^{\Delta}\right)$. Two types of the $\mathrm{SO} / \mathrm{FC}$ mechanism $\left(\mathrm{SO} / \mathrm{FC}^{\Delta}\right.$ in eq 6 and $\mathrm{SO} / \mathrm{FC}^{\nabla}$ in eq 7 ) involving contribution to $\sigma^{\mathrm{pSO}}(\mathrm{L})$ from MO69 are demonstrated for couplings

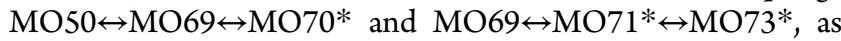
examples, in Figure S9 in the Supporting Information.

The important contribution to $\sigma^{\mathrm{pSO}}(\mathrm{L})$ from $\mathrm{MO} 69$ is represented by MO69 $\leftrightarrow$ MO71*↔MO69 coupling, involving the $\mathrm{SO} / \mathrm{FC}^{\Delta}$ mechanism. At the $1 \mathrm{c}$ level, the contribution to $\sigma^{\mathrm{p}}$ from $\mathrm{MO} 69 \leftrightarrow \mathrm{MO}^{*}$ is vanishingly small, but it gives rise to $\sigma^{\mathrm{p}}$ of about $-5 \mathrm{ppm}$ at the $2 \mathrm{c}$ level. The third-order perturbation $\mathrm{MO}$ analysis provides understanding of this difference, Figure 9c. The MO69 is coupled with MO71* by the spin-orbit operator $\left(r_{\mathrm{M}}^{-3} \hat{l}^{\mathrm{M}}\right)$ and the angular momentum operator $(\hat{l})$. The spin-orbit operator "generates" in the presence of a magnetic field an induced spin density on MO69. This spin density is then "measured" by the FC interaction operator $\left(\hat{\delta}^{L}\right.$ at the spectator nucleus $\left.L\right)$. The involvement of the FC operator implies a significant role of ligand $s$-character in MO69 (6\% C 2s). Note that the deshielding contribution of the $\mathrm{SO} / \mathrm{FC}^{\Delta}$ term (eq 6) is due to the coupling between two identical occupied $\sigma$-bonding $\mathrm{M}-\mathrm{L}$ orbitals MO69. This is in clear contrast to the shielding role of the vacant $\sigma$-antibonding $\mathrm{M}-\mathrm{L}$ orbital in Pt compound 4a, see Section 4.3.2.

4.3.2. Electronic Structure and Ligand NMR Shielding Constant in PyPt ${ }^{\prime \prime} \mathrm{Cl}\left(\mathrm{NH}_{3}\right) \mathrm{F}$ - Compound 4a. In contrast to mercury, platinum behaves as a "standard" $5 d$ transition metal. Therefore, $\sigma_{\mathrm{M}-\mathrm{L}}$-type MOs (MO69, MO65) are more stabilized in $\mathbf{4 a}$ as compared to those in $\mathbf{3 k}$ (MO69, MO61), see the magenta lines in Figure 8. Simultaneously, most of the $\pi$-type orbitals with Pt $5 \mathrm{~d}$ character (formal LPs and $\pi_{\mathrm{Pt}-\mathrm{N}}-$ type MOs) are considerably higher in energy when compared to those in 3k. This is highlighted by the light-green background in Figure 8. These changes are likely caused by a lower nuclear charge of platinum and its partly unfilled $5 d$-shell $\left(d^{8}\right)$. It should be explicitly noted that the total $\sigma^{\mathrm{P}}$ in $\mathbf{4 a}$ is dominated by the $\sigma_{\mathrm{M}-\mathrm{L}}$-type MOs at the $1 \mathrm{c}$ level similar to those in gold and mercury complexes. For example, MO69 ( $\sigma_{\mathrm{M}-\mathrm{L}}$-type $)$ with the nitrogen $2 p_{z}$ character contributes to $\sigma_{1 \mathrm{c}}^{\mathrm{p}}$ by $-56.5 \mathrm{ppm}$. This can be explained straightforwardly by the Ramsey-type (eq 4) magnetic coupling MO69 $\leftrightarrow$ MO79* $\left(\sigma^{\mathrm{p}}=-22 \mathrm{ppm}\right)$, where MO79* $\left(\pi_{\mathrm{M}-\mathrm{L}}\right.$-type $)$ has a significant nitrogen $2 p_{y}$ character (see Figure $10 \mathrm{a}$, cf. Figure $2 \mathrm{a}$ ). This coupling is induced by $\hat{l}_{x}$ and hence contributes to the tangential component of the NMR shielding tensor $\left(\sigma_{\mathrm{t}}^{\mathrm{p}}=-65 \mathrm{ppm}\right)$. However, this type of low-lying $\sigma$-type orbital in $4 \mathrm{a}$ is rather SO-intact.

The Dominant Role of Occupied $\pi$-Type $M-L$ Bonding MOs for $\sigma^{p S O}$. In general, total $\sigma^{\mathrm{pSO}}$ in $\mathbf{4 a}$ is dominated by numerous, albeit relatively small, contributions from upperlying $\pi$-type $\mathrm{M}-\mathrm{L}$ orbitals (see Figure 8 ) resulting in a large total $\sigma^{\mathrm{SO}}=+50.6 \mathrm{ppm}$. Interestingly, many of these MOs have shielding (positive) contributions to $\sigma^{\mathrm{p}}\left({ }^{15} \mathrm{~N}\right)$ even at the $1 \mathrm{c}$ level, although $\sigma^{\mathrm{p}}$ is generally associated with deshielding. ${ }^{35}$ For example, MO74 of N $2 p_{y}$ character and $\pi_{\mathrm{M}-\mathrm{L}^{-}}$type is efficiently coupled at $1 \mathrm{c}$ by the Ramsey-type mechanism to MO82* of $\mathrm{N}$ $2 p_{z}$ character and $\sigma_{\mathrm{M}-\mathrm{L}}$-type, providing thus shielding contribution, ${ }^{91,47}$ see Figure $10 \mathrm{~b}$. The total $\sigma^{\mathrm{p}}$ for MO74↔ MO82* is $+8 \mathrm{ppm}$ at $1 \mathrm{c}$ but amounts to $+11 \mathrm{ppm}$ at the $2 \mathrm{c}$ level $\left(\sigma^{\mathrm{pSO}}=+3 \mathrm{ppm}\right)$. Other examples of SO-induced shielding contributions of $\pi_{\mathrm{M}-\mathrm{L}}$ orbitals are (i) decreased deshielding for MO67 (-17.4 ppm at $1 \mathrm{c}$ vs $-10.4 \mathrm{ppm}$ at $2 \mathrm{c}$, $\left.\sigma^{\mathrm{pSO}}=+7.0 \mathrm{ppm}\right)$ and (ii) increased shielding for upper-lying MO71-78 $\left(\sum \sigma_{1 \mathrm{c}}^{\mathrm{p}}=+15.4 \mathrm{ppm}, \sum \sigma_{2 \mathrm{c}}^{\mathrm{p}}=+37.9 \mathrm{ppm}, \Sigma \sigma^{\mathrm{pSO}}=\right.$ $+22.5 \mathrm{ppm})$, see Figure 8 .

SO Contributions from Vacant M-L Antibonding MO82* to $\sigma^{p}(\mathrm{~L})$ : Analysis of Shielding Fermi-Contact Mechanism $\left(\mathrm{SO} / \mathrm{FC}^{\nabla}\right)$. To analyze the sign of $\sigma^{\mathrm{pSO}}(\mathrm{L})$ and to describe the mechanism of SO propagation, we performed the third-order 
perturbation $\mathrm{MO}$ analysis of $\mathrm{MO} 74 \leftrightarrow \mathrm{MO} 82 *$ coupling for $\mathrm{Pt}$ compound 4a (Figure 10c). As revealed by the analysis, the $\mathrm{SO} / \mathrm{FC}^{\nabla}$ mechanism plays a dominant role in which the MO74 is coupled with the MO82* by the spin-orbit operator $\left(r_{M}^{-3} \hat{l}^{M}\right)$ and the angular momentum operator $(\hat{l})$. The spin-orbit operator "generates" in the presence of a magnetic field an induced spin density on MO82*. This spin density is then "measured" by the FC interaction operator $\left(\hat{\boldsymbol{\delta}}^{L}\right)$ at the spectator nucleus L. Here, for the vacant $\sigma$-type $\mathrm{M}-\mathrm{L}$ antibonding orbital MO82*, the shielding contribution is dictated by the final positive sign of the $\mathrm{SO} / \mathrm{FC}^{\nabla}$ term (eq 7 ). This is in contrast with the deshielding role of occupied $\sigma$-type $\mathrm{M}-\mathrm{L}$ bonding orbitals in $\mathrm{Hg}$ compound 3k. To summarize, the sign of SO contributions to $\sigma^{\mathrm{p}}(\mathrm{L})$ is related to the character of the $\sigma_{\mathrm{M}-\mathrm{L}^{-}}$ space in frontier MOs. Whereas occupied $\sigma_{\mathrm{M}-\mathrm{L}}$-bonding MOs are linked to the deshielding SO effects on the atom $\mathrm{L}$ (e.g., $3 \mathrm{k})$, vacant $\sigma_{\mathrm{M}-\mathrm{L}}$-antibonding $\mathrm{MOs}$ are responsible for $\mathrm{SO}$ shielding (e.g., 4a). As the s-type AOs contribute exclusively to $\sigma$-bonding, their involvement in the $\sigma_{\mathrm{M}-\mathrm{L}} / \sigma^{*}{ }_{\mathrm{M}-\mathrm{L}}$-space is directly reflected in the sign of $\sigma^{\mathrm{pSO}}(\mathrm{L})$. This is intimately linked with the relative roles of $\sigma / \pi$ bonding between $\mathrm{M}$ and $\mathrm{L}$ discussed in Section 4.3.3.

4.3.3. The Role of $\sigma_{M-L}$ vs $\pi_{M-L}$ Bonds in Compounds $3 k$ $\left(\mathrm{PhHg}^{\prime \prime} \mathrm{SiH}_{3}\right)$ and $4 \mathrm{a}\left(\mathrm{PyPt}{ }^{\prime \prime} \mathrm{Cl}\left(\mathrm{NH}_{3}\right) \mathrm{F}\right)$ - NOCV Analysis. The important role of $\pi$-type $\mathrm{M}-\mathrm{L}$ bonding in $4 \mathrm{a}$ compared to $3 \mathrm{k}$ is clearly identified by EDA-NOCV analysis performed for these two compounds, see Figure 11. Whereas the $\mathrm{M}-\mathrm{L}$ bonding in $3 \mathrm{k}$ is largely of $\sigma$-character $\left(\frac{\mathrm{NOCV}_{1+3}}{\mathrm{NOCV}_{2}}=7.9\right.$, governed by metal $6 \mathrm{~s}$ $\mathrm{AO}$ contribution), the $\mathrm{M}-\mathrm{L}$ bonding in $4 \mathrm{a}$ has a significant contribution from the $\pi$-space $\left(\frac{\mathrm{NOCV}_{1}}{\mathrm{NOCV}_{2-4}}=2.6\right.$ with a significant contribution from metal $5 d \mathrm{AOs})$.

4.4. General Considerations. The trends and findings described above can be generalized. A schematic representation of the orbital space in selected complexes together with the $\sigma^{\text {sO }}$ values is given in Figure 12. The $\sigma$-type (red) and $\pi$-type $\mathrm{M}-\mathrm{L}$ or M (blue) orbitals are highlighted in relation to the metal $5 d$, $6 s$, and $6 p$ orbital space. Overall, the $\sigma^{\text {SO }}$ values correlate well with the electronic structure of the complexes (relative energetic positions of $\sigma$-type vs $\pi$-type MOs and metal $5 d$ vs $6 p$ character) and are modulated both by the different central atom $^{8,25}$ and the trans effect ${ }^{7,27}$ of ligand $\mathrm{X}$ (e.g., $\mathrm{F}$ vs $\mathrm{CH}_{3}$, $\left.\mathrm{SiH}_{3}\right)$.

Let us generalize our findings for the complexes in a series $5 d^{8}(+2)-5 d^{10} 6 s^{0}(+1)-5 d^{10} 6 s^{0}(+2)$, where the number in the bracket represents the formal charge of the central atom. Because of the partially open Pt $5 d$-shell in $4 a$, the highly positive $\sigma^{\mathrm{SO}}$ is dominated by the SO effects on the couplings among the occupied $\pi_{\mathrm{Pt}-\mathrm{L}}$ orbitals and vacant $\sigma_{\mathrm{Pt}-\mathrm{L}} *$ orbitals. Spin-orbit coupling modulates the energy and Pt $5 d$ character of both occupied and vacant orbitals, thus increasing the shielding and decreasing the deshielding $\mathrm{MO} \leftrightarrow \mathrm{MO}^{*}$ contributions (total $\sigma^{\mathrm{pSO}}>0$ in Figure 12). In 1a with a formally closed Au $5 d^{10}$ shell, the role of frontier $\pi_{\mathrm{Au}-\mathrm{L}}$ and $\pi_{\mathrm{LP}(\mathrm{Au})} \mathrm{MOs}$ in the SO shielding is significantly reduced. If the $\mathrm{Au}-\mathrm{L}$ bonding is additionally destabilized by a strong trans effect, like in the Au compound $\mathbf{1 i}$, the deshielding role of the occupied $\sigma_{\mathrm{Au}-\mathrm{L}}$ bonding orbitals starts to dominate the $\sigma^{\mathrm{SO}}$. Further, the paramagnetic SO deshielding is enhanced by admixing the metal $6 p$ orbitals into the frontier bonding $\sigma_{\mathrm{Hg}-\mathrm{L}} \mathrm{MOs}$ in $\mathrm{Hg}$ compound $3 \mathbf{k}$. These frontier orbitals (HOMO in $3 \mathbf{k}$ ) are efficiently coupled with the vacant $\pi^{*}$-type orbital space. The

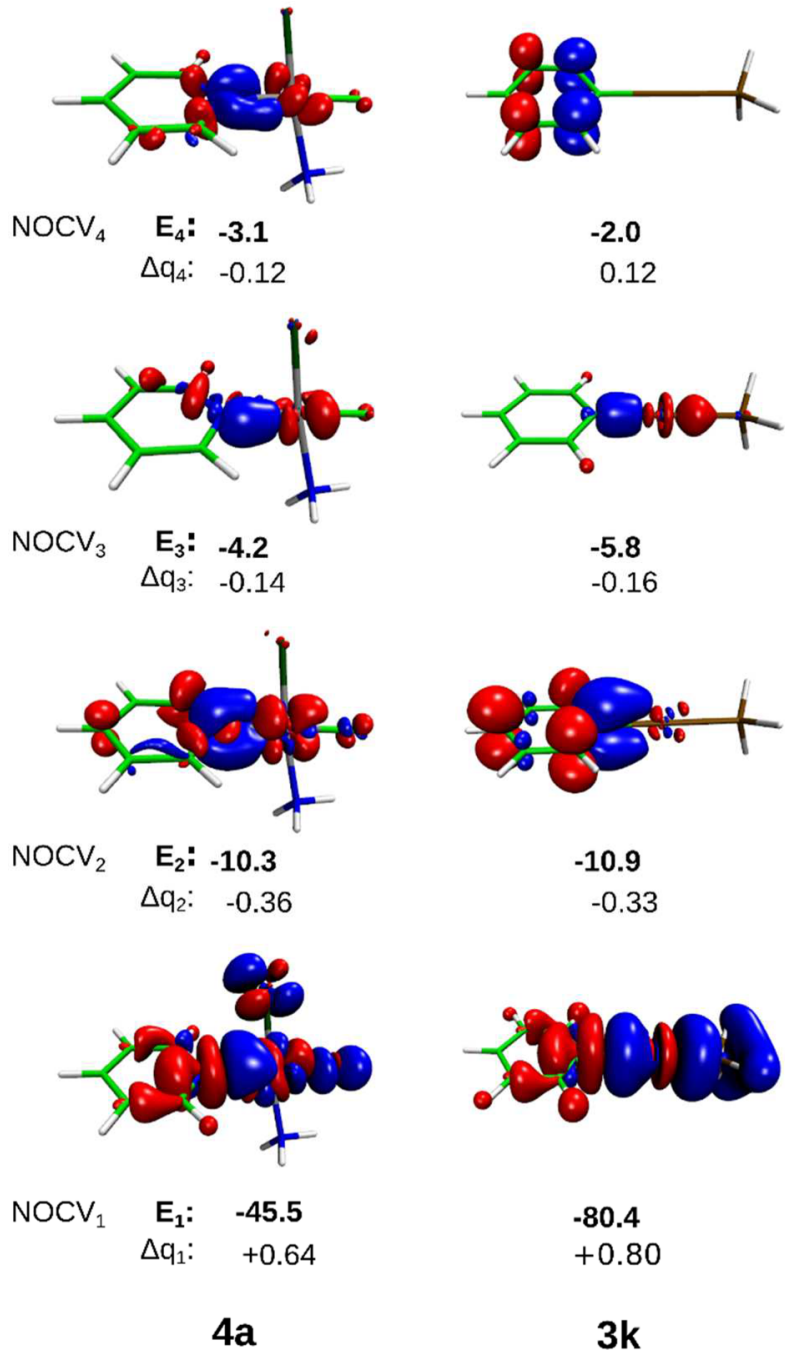

Figure 11. NOCV channels $\left(E_{n}-\right.$ energy stabilization, $\Delta q_{n}-$ transferred charge) for compounds $4 \mathbf{a}$ (left) and $3 \mathbf{k}$ (right). Note the significant difference in $\pi$-back bonding capabilities for $4 \mathbf{a}$ as compared to $3 \mathbf{k}$ indicated by $\mathrm{NOCV}_{2}-\mathrm{NOCV}_{4}$. NBO analysis of the $\mathrm{M}-\mathrm{L}$ bond indicates significantly lower contributions from the $d$-orbitals for $\mathbf{3 k}$ $[\mathrm{Hg} 34 \%(90 \% s, 1 \% \mathrm{p}, 9 \% \mathrm{~d})]$ compared to $4 \mathrm{a}$ [Pt 18\% (40\% s, 0\% p, $60 \% d)]$.

closed and significantly contracted $\mathrm{Hg} 5 d$ shell limits the contributions from $\pi_{\mathrm{Hg}-\mathrm{L}} \leftrightarrow \sigma_{\mathrm{Hg}-\mathrm{L}} *$ shielding couplings. In total, the SO effects induce increased deshielding in $3 \mathrm{k}\left(\sigma^{\mathrm{pSO}}<0\right.$, see Figure 12).

Interestingly, the above-mentioned SO-induced changes in MOs are nicely reflected in a rearrangement of the ground-state electron density upon the spin-orbit coupling. To make a link between these MO changes and $\sigma^{\mathrm{SO}}$, the SO-induced electron deformation density (SO-EDD), calculated as a difference between the electron density at $2 c$ and $1 c$ levels is visualized for compounds $\mathbf{4 a}$ and $3 \mathbf{k}$ in Figure 13. SO-alteration of the metal $\pi$-type orbitals (mainly $5 d$-based) in 4 a shifts the electron density from the metal $\pi$-space toward the connected ligand atoms (seen as shielding in Figure 12). In contrast, SOalteration of the metal $\sigma$-type orbitals (mainly $6 s$ - and $6 p$-based) in $3 \mathbf{k}$ induces accumulation of the electron density at the metal atom and its depletion at the neighboring ligand atoms (deshielding in Figure 12). 


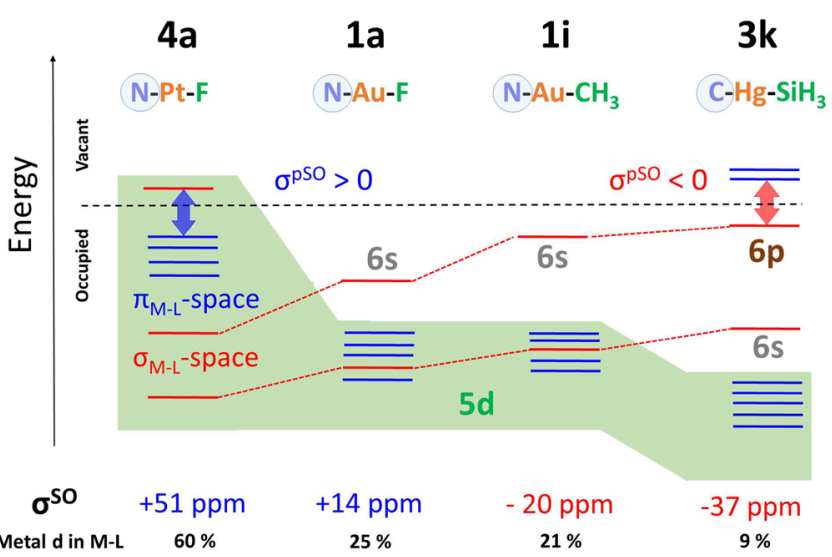

Figure 12. Schematic representation of the frontier MO energy levels in $4 \mathbf{a}, 1 \mathbf{a}, \mathbf{1} \mathbf{i}$, and $\mathbf{3 k}$ (from left to right) pointing to the shielding vs deshielding $\sigma^{\text {sO }}$. The ranges for MOs with metal $5 d$ character are highlighted by a green background, and the lines schematically represent $\pi$-type (blue) and $\sigma$-type (red) $\mathrm{M}-\mathrm{L}$ orbitals. The total $\sigma^{\text {sO }}$ values and metal $\mathrm{d}$ contributions to $\mathrm{M}-\mathrm{L}$ bonds (NBO analysis) are given at the bottom.

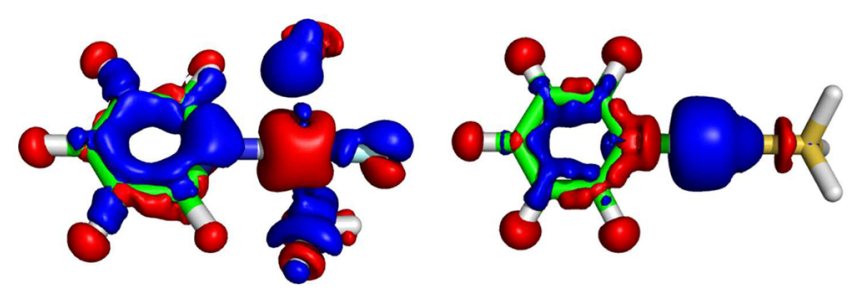

Figure 13. Spin-orbit-induced electron deformation density (SOEDD) for $4 \mathbf{a}$ vs $3 \mathbf{k}$ calculated as a difference between the electron densities at $2 \mathrm{c}$ and $1 \mathrm{c}$ levels.

\section{CONCLUDING REMARKS}

In the present work, a detailed analysis of the paramagnetic NMR shielding constants $\left(\sigma^{\mathrm{p}}\right)$ of the light atoms neighboring the heavy transition-metal centers in gold, mercury, and platinum complexes was performed, and intuitive chemical interpretations are provided. Particularly, we focused on the correlation between the metal-ligand $(\mathrm{M}-\mathrm{L})$ bonding characteristics and the sign of spin-orbit contributions to the ligand NMR shielding constants $\left(\sigma^{S O}\right)$. A thorough KohnSham molecular orbital (MO) analysis was performed, and the type and characteristics of MOs are correlated with $\sigma^{\mathrm{p}}$ and $\sigma^{\mathrm{SO}}$. The structural trans effect on the ligand NMR shielding constants in $\mathrm{Au}(\mathrm{I})$ compounds can be understood by changes in the relative roles of $\sigma$-type (bonding) and $\pi$-type (backbonding) $\mathrm{M}-\mathrm{L}$ orbitals. Furthermore, the shielding or deshielding nature of the spin-orbit contribution to $\sigma^{p}$ is naturally linked to the type of metal atom and its electronic structure. The dominating $\sigma$-type $6 s p$-based $\mathrm{M}-\mathrm{L}$ bonding in $\mathrm{Hg}(\mathrm{II})$ complexes is reflected in SO-induced deshielding, whereas the enhanced $\pi$-type $\mathrm{M}-\mathrm{L}$ bonding in $\mathrm{Pt}(\mathrm{II})$ complexes leads to SO-induced shielding. The details of metal-ligand bonding have been observed consistently in the energy and composition of MOs as well as characteristics obtained from the energy decomposition analysis linked with natural orbitals for chemical valence (EDA-NOCV). In addition, we analyzed the Fermi-contact mechanism of propagation of the SO effect from the metal center to the ligand atom modulating individual components of the para- magnetic NMR shielding tensor of the ligand atom. Finally, we demonstrate an intuitive chemical link between the SO-induced changes in NMR shielding constants and the SO-induced changes in electron density (SO-EDD, spin-orbit-induced electron deformation density) around the metal and ligand atom. Investigations of how general these trends are along the Periodic Table are underway with our team.

\section{ASSOCIATED CONTENT}

\section{Supporting Information}

The Supporting Information is available free of charge on the ACS Publications website at DOI: 10.1021/acs.jctc.7b00444.

Tables S1-S13: SO/FC and SO/SD contributions, $\sigma^{\mathrm{SO}}(\mathrm{L})$ values, $\mathrm{MO}$ contributions, EDA-NOCV analysis, and DI values for complexes 1-4 with orientations of the principal components of the NMR shielding tensors; Figures S1-S8: energy diagrams and orbital contributions to $\sigma^{\mathrm{p}}$ from the frontier occupied Kohn-Sham MOs for 1a, 1i, 3k, and 4a at 1c, 2c, and 4c levels; Figure S9: schematic representations of SO-induced MO magnetic couplings (the SO/FC mechanism); Cartesian coordinates for $1 \mathrm{a}, \mathbf{1 i}, \mathbf{3 k}$, and $\mathbf{4 a}(\mathrm{PDF})$

\section{AUTHOR INFORMATION}

\section{Corresponding Authors}

*E-mail: stanislav.komorovsky@savba.sk (S.K.).

*E-mail: radek.marek@ceitec.muni.cz (R.M.).

ORCID $\odot$

Jan Vícha: 0000-0003-3698-8236

Michal Straka: 0000-0002-7857-4990

Stanislav Komorovsky: 0000-0002-5317-7200

Radek Marek: 0000-0002-3668-3523

\section{Author Contributions}

J.N., J.V., and P.L.B. contributed equally to this work.

\section{Funding}

This work was supported by the Czech Science Foundation (16-05961S and 15-09381S) and partly by the Ministry of Education, Youth and Sports of the Czech Republic under the National Sustainability Program II (LQ1601) and I (LO1504) as well as the multilateral cooperation project (8X17009). Financial support was received from the SASPRO Program (1563/03/02), cofinanced by the European Union and the Slovak Academy of Sciences, the Grant Agency of the Ministry of Education of the Slovak Republic and Slovak Academy of Sciences VEGA (2/0116/17), and the Research Council of Norway (179568). Computational resources were provided by the CESNET (LM2015042), the CERIT Scientific Cloud (LM2015085), and the Norwegian supercomputing program NOTUR (NN4654K).

\section{Notes}

The authors declare no competing financial interest.

A related work on ${ }^{1} \mathrm{H}$ NMR shielding constants in some transition-metal complexes, highlighting the role of $\sigma$ - and $\pi$ type MOs, appeared during the finalization of this manuscript. $^{92}$

\section{REFERENCES}

(1) Multidimensional NMR Methods for the Solution State, 1st ed.; Morris, G. A., Emsley, J. W., Eds.; Wiley: Chichester, U.K, 2010; pp 1-580, DOI: 10.1080/0889311X.2011.608355. 
(2) Kumar, A.; Grace, R. C. R.; Madhu, P. K. Cross-Correlations in NMR. Prog. Nucl. Magn. Reson. Spectrosc. 2000, 37, 191-319.

(3) Kowalewski, J.; Maler, L. Nuclear Spin Relaxation in Liquids: Theory, Experiments, and Applications, 1st ed.; CRC Press: New York, 2006; pp 1-440.

(4) Ramsey, N. F. Magnetic Shielding of Nuclei in Molecules. Phys. Rev. 1950, 78, 699-703.

(5) Marek, R. 15N NMR Applications. In Encyclopedia of Spectroscopy and Spectrometry, 2nd ed.; Lindon, J. C., Ed.; Academic Press: Oxford, 2010; pp 1892-1898.

(6) Pyykkö, P. Relativistic Effects in Structural Chemistry. Chem. Rev. 1988, 88, 563-594.

(7) Vícha, J.; Straka, M.; Munzarová, M. L.; Marek, R. Mechanism of Spin-Orbit Effects on the Ligand NMR Chemical Shift in TransitionMetal Complexes: Linking NMR to EPR. J. Chem. Theory Comput. 2014, 10, 1489-1499.

(8) Vícha, J.; Foroutan-Nejad, C.; Pawlak, T.; Munzarová, M. L.; Straka, M.; Marek, R. Understanding the Electronic Factors Responsible for Ligand Spin-Orbit NMR Shielding in TransitionMetal Complexes. J. Chem. Theory Comput. 2015, 11, 1509-1517.

(9) Vícha, J.; Novotný, J.; Straka, M.; Repisky, M.; Ruud, K.; Komorovsky, S.; Marek, R. Structure, Solvent, and Relativistic Effects on the NMR Chemical Shifts in Square-Planar Transition-Metal Complexes: Assessment of DFT Approaches. Phys. Chem. Chem. Phys. 2015, 17, 24944-24955.

(10) Nakatsuji, H.; Takashima, H.; Hada, M. Spin-Orbit Effect on the Magnetic Shielding Constant Using the Ab Initio UHF Method. Chem. Phys. Lett. 1995, 233, 95-101.

(11) Kaupp, M.; Malkina, O. L.; Malkin, V. G.; Pyykkö, P. How Do Spin-Orbit-Induced Heavy-Atom Effects on NMR Chemical Shifts Function? Validation of a Simple Analogy to Spin-Spin Coupling by Density Functional Theory (DFT) Calculations on Some Iodo Compounds. Chem. - Eur. J. 1998, 4, 118-126.

(12) Pyykkö, P.; Görling, A. A Transparent Interpretation of the Relativistic Contribution to the N.M.R. 'Heavy Atom Chemical Shift.'. Mol. Phys. 1987, 61, 195-205.

(13) Helgaker, T.; Jaszuński, M.; Ruud, K. Ab Initio Methods for the Calculation of NMR Shielding and Indirect Spin-Spin Coupling Constants. Chem. Rev. 1999, 99, 293-352.

(14) Autschbach, J.; Ziegler, T. In Encyclopedia of Nuclear Magnetic Resonance, Vol. 9, Advances in NMR; John Wiley and Sons: Chichester, 2002; pp 306-323.

(15) Vaara, J. Theory and Computation of Nuclear Magnetic Resonance Parameters. Phys. Chem. Chem. Phys. 2007, 9, 5399.

(16) Malkina, O. L.; Schimmelpfennig, B.; Kaupp, M.; Hess, B. A.; Chandra, P.; Wahlgren, U.; Malkin, V. G. Spin-orbit Corrections to NMR Shielding Constants from Density Functional Theory. How Important Are the Two-Electron Terms? Chem. Phys. Lett. 1998, 296, 93-104.

(17) Manninen, P.; Lantto, P.; Vaara, J.; Ruud, K. Perturbational Ab Initio Calculations of Relativistic Contributions to Nuclear Magnetic Resonance Shielding Tensors. J. Chem. Phys. 2003, 119, 2623-2637.

(18) Wolff, S. K.; Ziegler, T. Calculation of DFT-GIAO NMR Shifts with the Inclusion of Spin-Orbit Coupling. J. Chem. Phys. 1998, 109, 895-905.

(19) Nakagawa, N.; Sinada, S.; Obinata, S. The 6th NMR Symposium. 6th NMR Symp. 1967, 8-8.

(20) Nomura, Y.; Takeuchi, Y.; Nakagawa, N. Substituent Effects in Aromatic Proton Nmr Spectra. III Substituent Effects Caused by Halogens. Tetrahedron Lett. 1969, 10, 639-642.

(21) Cheremisin, A. A.; Schastnev, P. V. Effects of Spin-Orbital Interactions on 13C NMR Chemical Shifts in Halogen-Substituted Methanes. J. Magn. Reson. 1980, 40, 459-468.

(22) Hegetschweiler, K.; Kuppert, D.; Huppert, J.; Straka, M.; Kaupp, M. Spin-Orbit-Induced Anomalous PH-Dependence in $1 \mathrm{H}$ NMR Spectra of CoIII Amine Complexes: A Diagnostic Tool for Structure Elucidation. J. Am. Chem. Soc. 2004, 126, 6728-6738.

(23) Hyvärinen, M.; Vaara, J.; Goldammer, A.; Kutzky, B.; Hegetschweiler, K.; Kaupp, M.; Straka, M. Characteristic Spin-Orbit
Induced $1 \mathrm{H}(\mathrm{CH} 2)$ Chemical Shifts upon Deprotonation of Group 9 Polyamine Aqua and Alcohol Complexes. J. Am. Chem. Soc. 2009, 131, 11909-11918.

(24) Kaupp, M.; Malkina, O. L.; Malkin, V. G. The Role of $\pi$-Type Nonbonding Orbitals for Spin-orbit Induced NMR Chemical Shifts: DFT Study of $13 \mathrm{C}$ and 19F Shifts in the Series CF3IFn $(\mathrm{N}=0,2,4$, 6). J. Comput. Chem. 1999, 20, 1304-1313.

(25) Pawlak, T.; Munzarová, M. L.; Pazderski, L.; Marek, R. Validation of Relativistic DFT Approaches to the Calculation of NMR Chemical Shifts in Square-Planar Pt2+ and Au3+ Complexes. J. Chem. Theory Comput. 2011, 7, 3909-3923.

(26) Truflandier, L. A.; Brendler, E.; Wagler, J.; Autschbach, J. 29Si DFT/NMR Observation of Spin-Orbit Effect in Metallasilatrane Sheds Some Light on the Strength of the Metal $\rightarrow$ Silicon Interaction. Angew. Chem., Int. Ed. 2011, 50, 255-259.

(27) Vícha, J.; Patzschke, M.; Marek, R. A Relativistic DFT Methodology for Calculating the Structures and NMR Chemical Shifts of Octahedral Platinum and Iridium Complexes. Phys. Chem. Chem. Phys. 2013, 15, 7740-7754.

(28) Greif, A. H.; Hrobárik, P.; Hrobáriková, V.; Arbuznikov, A. V.; Autschbach, J.; Kaupp, M. A Relativistic Quantum-Chemical Analysis of the trans Influence on $1 \mathrm{H}$ NMR Hydride Shifts in Square-Planar Platinum(II) Complexes. Inorg. Chem. 2015, 54, 7199-7208.

(29) Burdett, J. K.; Albright, T. A. Trans Influence and Mutual Influence of Ligands Coordinated to a Central Atom. Inorg. Chem. 1979, 18, 2112-2120.

(30) Mitoraj, M. P.; Zhu, H.; Michalak, A.; Ziegler, T. On the Origin of the Trans-Influence in Square Planar D8-Complexes: A Theoretical Study. Int. J. Quantum Chem. 2009, 109, 3379-3386.

(31) Ruiz-Morales, Y.; Schreckenbach, G.; Ziegler, T. Origin of the Hydridic $1 \mathrm{H}$ NMR Chemical Shift in Low-Valent Transition-Metal Hydrides. Organometallics 1996, 15, 3920-3923.

(32) Solum, M. S.; Altmann, K. L.; Strohmeier, M.; Berges, D. A.; Zhang, Y.; Facelli, J. C.; Pugmire, R. J.; Grant, D. M. 15N Chemical Shift Principal Values in Nitrogen Heterocycles. J. Am. Chem. Soc. 1997, 119, 9804-9809.

(33) Marek, R.; Brus, J.; Toušek, J.; Kovács, L.; Hocková, D. N7- and N9-Substituted Purine Derivatives: A 15N NMR Study. Magn. Reson. Chem. 2002, 40, 353-360.

(34) Marek, R.; Lyčka, A.; Kolehmainen, E.; Sievänen, E.; Toušek, J. 15N NMR Spectroscopy in Structural Analysis. An Update 20012005. Curr. Org. Chem. 2007, 11, 1154-1205.

(35) Standara, S.; Bouzková, K.; Straka, M.; Zacharová, Z.; Hocek, M.; Marek, J.; Marek, R. Interpretation of Substituent Effects on 13C and 15N NMR Chemical Shifts in 6-Substituted Purines. Phys. Chem. Chem. Phys. 2011, 13, 15854-15864.

(36) Malkina, O. L.; Komorovský, S.; Visscher, L.; Malkin, V. G. Note: Counterintuitive Gauge-Dependence of Nuclear Magnetic Resonance Shieldings for Rare-Gas Dimers: Does a Natural GaugeOrigin for Spherical Atoms Exist? J. Chem. Phys. 2011, 134, 086101.

(37) Standara, S.; Maliňáková, K.; Marek, R.; Marek, J.; Hocek, M.; Vaara, J.; Straka, M. Understanding the NMR chemical shifts for 6halopurines: role of structure, solvent and relativistic effects. Phys. Chem. Chem. Phys. 2010, 12, 5126-5139.

(38) Adamo, C.; Barone, V. Toward Reliable Density Functional Methods without Adjustable Parameters: The PBE0Model. J. Chem. Phys. 1999, 110, 6158-6170.

(39) Weigend, F.; Ahlrichs, R. Balanced Basis Sets of Split Valence, Triple Zeta Valence and Quadruple Zeta Valence Quality for H to Rn: Design and Assessment of Accuracy. Phys. Chem. Chem. Phys. 2005, 7, 3297-3305.

(40) TURBOMOLE V6.3 2011; Development of University of Karlsruhe and Forschungszentrum Karlsruhe GmbH, 1989-2007, TURBOMOLE GmbH: since 2007. Available from http://www. Turbomole.Com (accessed January 21, 2015).

(41) Andrae, D.; Häußermann, U.; Dolg, M.; Stoll, H.; Preuß, H. Energy-Adjustedab Initio Pseudopotentials for the Second and Third Row Transition Elements. Theor. Chim. Acta 1990, 77, 123-141. 
(42) Bühl, M. Density Functional Computations of Transition Metal NMR Chemical Shifts: Dramatic Effects of Hartree-Fock Exchange. Chem. Phys. Lett. 1997, 267, 251-257.

(43) Bühl, M.; Kabrede, H. Geometries of Transition-Metal Complexes from Density-Functional Theory. J. Chem. Theory Comput. 2006, 2, 1282-1290.

(44) Bühl, M.; Reimann, C.; Pantazis, D. A.; Bredow, T.; Neese, F. Geometries of Third-Row Transition-Metal Complexes from DensityFunctional Theory. J. Chem. Theory Comput. 2008, 4, 1449-1459.

(45) Novotný, J.; Sojka, M.; Komorovsky, S.; Nečas, M.; Marek, R. Interpreting the Paramagnetic NMR Spectra of Potential $\mathrm{Ru}(\mathrm{III})$ Metallodrugs: Synergy between Experiment and Relativistic DFT Calculations. J. Am. Chem. Soc. 2016, 138, 8432-8445.

(46) Autschbach, J. Analyzing NMR Shielding Tensors Calculated with Two-Component Relativistic Methods Using Spin-Free Localized Molecular Orbitals. J. Chem. Phys. 2008, 128, 164112-164123.

(47) Autschbach, J.; Zheng, S. Analyzing Pt Chemical Shifts Calculated from Relativistic Density Functional Theory Using Localized Orbitals: The Role of Pt $5 \mathrm{~d}$ Lone Pairs. Magn. Reson. Chem. 2008, 46, S45-S55.

(48) Van Lenthe, E.; Baerends, E. J. Optimized Slater-Type Basis Sets for the Elements 1-118. J. Comput. Chem. 2003, 24, 1142-1156.

(49) Chong, D. P.; Van Lenthe, E.; Van Gisbergen, S.; Baerends, E. J. Even-Tempered Slater-Type Orbitals Revisited: From Hydrogen to Krypton. J. Comput. Chem. 2004, 25, 1030-1036.

(50) van Lenthe, E.; Baerends, E. J.; Snijders, J. G. Relativistic Total Energy Using Regular Approximations. J. Chem. Phys. 1994, 101, 9783-9792.

(51) van Lenthe, E.; Baerends, E. J.; Snijders, J. G. Relativistic Regular Two-component Hamiltonians. J. Chem. Phys. 1993, 99, 4597-4610.

(52) van Lenthe, E.; Snijders, J. G.; Baerends, E. J. The Zero-order Regular Approximation for Relativistic Effects: The Effect of Spinorbit Coupling in Closed Shell Molecules. J. Chem. Phys. 1996, 105, 6505-6516.

(53) Mitoraj, M. P.; Michalak, A.; Ziegler, T. A Combined Charge and Energy Decomposition Scheme for Bond Analysis. J. Chem. Theory Comput. 2009, 5, 962-975.

(54) von Hopffgarten, M.; Frenking, G. Energy Decomposition Analysis. Wiley Interdiscip. Rev. Comput. Mol. Sci. 2012, 2, 43-62.

(55) Bickelhaupt, F. M.; Baerends, E. J. Kohn-Sham Density Functional Theory: Predicting and Understanding Chemistry. In Reviews in Computational Chemistry; Lipkowitz, K. B., Boyd, D. B., Eds.; John Wiley \& Sons, Inc.: 2000; pp 1-86, DOI: 10.1002/ 9780470125922.ch1.

(56) Ziegler, T.; Rauk, A. A Theoretical Study of the Ethylene-Metal Bond in Complexes between Copper(1+), Silver(1+), Gold(1+), Platinum(0) or Platinum(2+) and Ethylene, Based on the HartreeFock-Slater Transition-State Method. Inorg. Chem. 1979, 18, 15581565.

(57) Ziegler, T.; Rauk, A. Carbon Monoxide, Carbon Monosulfide, Molecular Nitrogen, Phosphorus Trifluoride, and Methyl Isocyanide as.Sigma. Donors and.Pi. Acceptors. A Theoretical Study by the Hartree-Fock-Slater Transition-State Method. Inorg. Chem. 1979, 18, $1755-1759$.

(58) Ziegler, T.; Rauk, A. On the Calculation of Bonding Energies by the Hartree Fock Slater Method. Theor. Chim. Acta 1977, 46, 1-10.

(59) Mitoraj, M.; Michalak, A. Natural Orbitals for Chemical Valence as Descriptors of Chemical Bonding in Transition Metal Complexes. J. Mol. Model. 2007, 13, 347-355.

(60) Bouzková, K.; Babinský, M.; Novosadová, L.; Marek, R. Intermolecular Interactions in Crystalline Theobromine as Reflected in Electron Deformation Density and 13C NMR Chemical Shift Tensors. J. Chem. Theory Comput. 2013, 9, 2629-2638.

(61) Babinský, M.; Bouzková, K.; Pipiška, M.; Novosadová, L.; Marek, R. Interpretation of Crystal Effects on NMR Chemical Shift Tensors: Electron and Shielding Deformation Densities. J. Phys. Chem. A 2013, 117, 497-503.
(62) Keith, T. A.; Frisch, M. J. Subshell Fitting of Relativistic Atomic Core Electron Densities for Use in QTAIM Analyses of ECP-Based Wave Functions. J. Phys. Chem. A 2011, 115, 12879-12894.

(63) Keith, T. A. AIMAll (Version 14.06.21); TK Gristmill Software: Overland Park, KS, USA, 2014. www.tkgristmill.com (accessed June $10,2015)$.

(64) Cortés-Guzmán, F.; Bader, R. F. W. Complementarity of QTAIM and MO Theory in the Study of Bonding in Donor-acceptor Complexes. Coord. Chem. Rev. 2005, 249, 633-662.

(65) te Velde, G.; Bickelhaupt, F. M.; Baerends, E. J.; Fonseca Guerra, C.; van Gisbergen, S. J. A.; Snijders, J. G.; Ziegler, T. Chemistry with ADF. J. Comput. Chem. 2001, 22, 931-967.

(66) Fonseca Guerra, C. F.; Snijders, J. G.; te Velde, G.; Baerends, E. J. Towards an Order-N DFT Method. Theor. Chem. Acc. 1998, 99, 391-403.

(67) Wolinski, K.; Hinton, J. F.; Pulay, P. Efficient Implementation of the Gauge-Independent Atomic Orbital Method for NMR Chemical Shift Calculations. J. Am. Chem. Soc. 1990, 112, 8251-8260.

(68) Vícha, J.; Demo, G.; Marek, R. Platinum-Modified Adenines: Unprecedented Protonation Behavior Revealed by NMR Spectroscopy and Relativistic Density-Functional Theory Calculations. Inorg. Chem. 2012, 51, 1371-1379.

(69) Komorovsky, S.; Repisky, M.; Malkina, O. L.; Malkin, V. G.; Malkin Ondík, I.; Kaupp, M. A Fully Relativistic Method for Calculation of Nuclear Magnetic Shielding Tensors with a Restricted Magnetically Balanced Basis in the Framework of the Matrix DiracKohn-Sham Equation. J. Chem. Phys. 2008, 128, 104101-104115.

(70) Komorovsky, S.; Repisky, M.; Malkina, O. L.; Malkin, V. G. Fully Relativistic Calculations of NMR Shielding Tensors Using Restricted Magnetically Balanced Basis and Gauge Including Atomic Orbitals. J. Chem. Phys. 2010, 132, 154101-154108.

(71) Repisky, M.; Komorovsky, S.; Malkin, V. G.; Malkina, O. L.; Kaupp, M.; Ruud, K.; Bast, R.; Ekstrom, U.; Kadek, M.; Knecht, S.; Konečný, L.; Malkin, E.; Malkin Ondík, I. Relativistic Spectroscopy DFT Program ReSpect, Developer Version 4.0.0; 2017. www.respectprogram. org (accessed February 9, 2017).

(72) Perdew, J.; Burke, K.; Ernzerhof, M. Erratum: Generalized Gradient Approximation Made Simple. Phys. Rev. Lett. 1997, 78, 1396-1396.

(73) Dyall, K. G. Relativistic Double-Zeta, Triple-Zeta, and Quadruple-Zeta Basis Sets for the 5d Elements Hf-Hg. Theor. Chem. Acc. 2004, 112, 403-409.

(74) Dyall, K. G. Relativistic Double-Zeta, Triple-Zeta, and Quadruple-Zeta Basis Sets for the 4d Elements Y-Cd. Theor. Chem. Acc. 2007, 117, 483-489.

(75) Dyall, K. G.; Gomes, A. S. P. Revised Relativistic Basis Sets for the 5d Elements Hf-Hg. Theor. Chem. Acc. 2010, 125, 97-100.

(76) Vícha, J.; Marek, R.; Straka, M. High-Frequency 13C and 29Si NMR Chemical Shifts in Diamagnetic Low-Valence Compounds of TlI and PbII: Decisive Role of Relativistic Effects. Inorg. Chem. 2016, $55,1770-1781$.

(77) Vícha, J.; Marek, R.; Straka, M. High-Frequency 1H NMR Chemical Shifts of SnII and PbII Hydrides Induced by Relativistic Effects: Quest for PbII Hydrides. Inorg. Chem. 2016, 55, 1030210309.

(78) Gohr, S.; Hrobárik, P.; Repisky, M.; Komorovsky, S.; Ruud, K.; Kaupp, M. Four-Component Relativistic Density Functional Theory Calculations of EPR g- and Hyperfine-Coupling Tensors Using Hybrid Functionals: Validation on Transition-Metal Complexes with Large Tensor Anisotropies and Higher-Order Spin-Orbit Effects. J. Phys. Chem. A 2015, 119, 12892-12905.

(79) Olsen, J.; Jørgensen, P. Linear and Nonlinear Response Functions for an Exact State and for an MCSCF State. J. Chem. Phys. 1985, 82, 3235-3264.

(80) Melo, J. I.; Ruiz de Azua, M. C.; Giribet, C. G.; Aucar, G. A.; Provasi, P. F. Relativistic Effects on Nuclear Magnetic Shielding Constants in $\mathrm{HX}$ and $\mathrm{CH} 3 \mathrm{X}(\mathrm{X}=\mathrm{Br}, \mathrm{I})$ Based on the Linear Response within the Elimination of Small Component Approach. J. Chem. Phys. 2004, 121, 6798-6808. 
(81) Marek, R.; Sklenář, V. NMR Studies of Purines. In Annual Reports on NMR Spectroscopy; Academic Press: 2004; Vol. 54, pp 201242, DOI: $10.1016 /$ S0066-4103(04)54005-X.

(82) Minaev, B.; Vaara, J.; Ruud, K.; Vahtras, O.; Ågren, H. Internuclear Distance Dependence of the Spin-orbit Coupling Contributions to Proton NMR Chemical Shifts. Chem. Phys. Lett. 1998, 295, 455-461.

(83) Rafat, M.; Popelier, P. L. A. Topological Atom-Atom Partitioning of Molecular Exchange Energy and Its Multipolar Convergence. In The Quantum Theory of Atoms in Molecules; Matta, C. F., Boyd, R. J., Eds.; Wiley-VCH: 2007; pp 121-140, DOI: 10.1002/9783527610709.ch5

(84) Foroutan-Nejad, C.; Badri, Z.; Marek, R. Multi-Center Covalency: Revisiting the Nature of Anion $-\pi$ Interactions. Phys. Chem. Chem. Phys. 2015, 17, 30670-30679.

(85) Datta, D. Ab Initio Calculations, Electronegativity Equalisation and Group Electronegativity. Proc. Indian Acad. Sci. - Chem. Sci. 1988, $100,549-557$.

(86) Mullay, J. Atomic and Group Electronegativities. J. Am. Chem. Soc. 1984, 106, 5842-5847.

(87) Mullay, J. Calculation of Group Electronegativity. J. Am. Chem. Soc. 1985, 107, 7271-7275.

(88) Salvi, N.; Belpassi, L.; Tarantelli, F. On the Dewar-ChattDuncanson Model for Catalytic Gold(I) Complexes. Chem. - Eur. J. 2010, 16, 7231-7240.

(89) Hrobárik, P.; Hrobáriková, V.; Meier, F.; Repisky, M.; Komorovsky, S.; Kaupp, M. Relativistic Four-Component DFT Calculations of $1 \mathrm{H}$ NMR Chemical Shifts in Transition-Metal Hydride Complexes: Unusual High-Field Shifts Beyond the BuckinghamStephens Model. J. Phys. Chem. A 2011, 115, 5654-5659.

(90) Wodyński, A.; Gryff-Keller, A.; Pecul, M. The Influence of a Presence of a Heavy Atom on 13C Shielding Constants in Organomercury Compounds and Halogen Derivatives. J. Chem. Theory Comput. 2013, 9, 1909-1917.

(91) Wiberg, K. B.; Hammer, J. D.; Zilm, K. W.; Cheeseman, J. R. NMR Chemical Shifts. 3. A Comparison of Acetylene, Allene, and the Higher Cumulenes. J. Org. Chem. 1999, 64, 6394-6400.

(92) Greif, A. H.; Hrobarik, P.; Kaupp, M. Insights into Trans-Ligand and Spin-Orbit Effects on Electronic Structure and Ligand NMR Shifts in Transition-Metal Complexes. Chem. - Eur. J. 2017, DOI: 10.1002/ chem.201701751. 